University of Louisville

ThinkIR: The University of Louisville's Institutional Repository

$5-2014$

\title{
Completing the journey : an exploratory study of factors predicting emotional distress in recently resettled adult refugees.
}

Susan Heffner Rhema

University of Louisville

Follow this and additional works at: https://ir.library.louisville.edu/etd

Part of the Social Work Commons

\section{Recommended Citation}

Rhema, Susan Heffner, "Completing the journey : an exploratory study of factors predicting emotional distress in recently resettled adult refugees." (2014). Electronic Theses and Dissertations. Paper 1199. https://doi.org/10.18297/etd/1199

This Doctoral Dissertation is brought to you for free and open access by ThinkIR: The University of Louisville's Institutional Repository. It has been accepted for inclusion in Electronic Theses and Dissertations by an authorized administrator of ThinkIR: The University of Louisville's Institutional Repository. This title appears here courtesy of the author, who has retained all other copyrights. For more information, please contact thinkir@louisville.edu. 
COMPLETING THE JOURNEY: AN EXPLORATORY STUDY OF FACTORS PREDICTING EMOTIONAL DISTRESS IN RECENTLY RESETTLED ADULT REFUGEES

By
Susan Heffner Rhema
A.B., Albright College, 1980
M.S.W., University of Maryland, School of Social Work and Community Planning, 1983

A Dissertation submitted to

the Faculty of Raymond A. Kent School of Social Work

of the University of Louisville in Partial Fulfillment of

the requirements of the Degree of

Doctor of Philosophy

Kent School of Social Work

University of Louisville

Louisville, KY

May 2014 
Copyright 2014 by Susan Heffner Rhema

All rights reserved 

COMPLETING THE JOURNEY:

AN EXPLORATORY STUDY OF FACTORS PREDICTING EMOTIONAL DISTRESS IN RECENTLY RESETTLED ADULT REFUGEES

by

Susan Heffner Rhema

A.B., Albright College, 1980

M.S.W., University of Maryland, School of Social Work and Community Planning, 1983

A Dissertation approved on

April 14, 2014

by the following Dissertation Committee:

Dissertation Chair
Dr Bibhuti Sar

Dr. Thomas Lawson

Dr. Pamela Yankeelov

Dr. Andrian Archeleta

Dr. Marie Antoinette Sossou 


\section{DEDICATION}

This work is dedicated

to the hundreds of refugees who have honored me by sharing their journey,

and

to my family who have accompanied me to fulfilling my dream,

my husband, Dan,

my daughters, Sydel, Kendall and Alexandra,

my son Sadiq,

my grandchildren, Natalie and Zakariya,

and Ann. 


\section{ACKNOWLEDGEMENTS}

This study would not have been possible without the Pathways to Wellness team whose diligent work and devotion to the service of refugees in Seattle, Washington led to the collection of this data. I am especially grateful to Beth Farmer and Sasha VerbillisKolp, for trusting me with the data set, answering my many questions about the research process and to their ongoing work with refugees.

I am also very appreciative of the members of my dissertation committee who spent many hours reading, providing feedback and sharing resources. Each member contributed to the final product of this document in their own way, giving expertise, guidance, and support. I am grateful for their contributions, for setting a standard for which to achieve and for their sense of humor when I needed it most. My deep appreciation to Dr. Bibhuti Sar for leading the process and for his commitment to work with refugees, and in turn, to me. I am also very grateful to each member for their unique knowledge and direction, Dr. Tom Lawson, Dr. Pamela Yankeelov, Dr. Adrian Archuleta, and Dr. Marie-Antoinette Sossou.

And, finally, I want to acknowledge a mentor and colleague, without whom I could not have completed this work, Dr. Michael Hollifield. As the Evaluation Director for the Pathways to Wellness study, Dr. Hollifield has been generous in sharing his work and his time. However, more importantly, Dr. Hollifield has shared his invaluable insights, his extensive knowledge and his creative expertise with me. I look forward to our continued work together and our ongoing friendship. 


\title{
ABSTRACT \\ COMPLETING THE JOURNEY: AN EXPLORATORY STUDY OF FACTORS PREDICTING EMOTIONAL DISTRESS IN RECENTLY RESETTLED ADULT REFUGEES
}

\author{
Susan Heffner Rhema
}

April 14, 2014

In the fiscal year 2010 a total of 73, 311 refugees arrived to the United States from over 70 countries. Along with their rich cultural practices, refugees bring loss, significant trauma and challenges related to migration. Their hope for the future is often overshadowed by the stresses inherent in adapting to new social expectations. Yet, after enduring a period of transition, most refugees become productive members of their community.

This study analyzes prearrival characteristics, (demographic traits, self-efficacy, prearrival trauma, and living location), and post arrival perceptions, (conservation of resources and number of postarrival problems), in predicting emotional distress, (anxiety, depression), in refugees at the early stage of resettlement. With limited research on the relationship between refugee stress, self-efficacy, and conservation of resources this research adds to the empirical data. Increased knowledge about these factors improves insight into the refugee experience in the early days of migration and can enhance social work models for intervention at this stage of resettlement.

An exploratory preexperimental, one-group design was used to identify the most significant factors predictive of anxiety and depression in refugees shortly after arrival to 
the US. The sample included 170 refugees from Burma, Iraq, and Nepal in the second and third month after arrival to Seattle, Washington in 2010. Measures used in this study include the Hopkins Symptom Checklist, (HSCL-25), Generalized Self-efficacy (GSE), Conservation of Resources (COR), Comprehensive Trauma Inventory (CTI), and the Post Migration Living Problems (PMLP). Three pairs of simultaneous binary logistic regressions identified the most predictive factors of anxiety and depression.

Of these factors the most predictive of both anxiety and depression were selfefficacy and perceived resource loss. The factors that most strongly predicted anxiety alone were gender and number of postarrival problems. The factor that most strongly predicted depression alone was number of prearrival traumas.

While most studies of refugees focus on the refugee history of trauma, this study explores a broad range of factors that support or impede migration adaptation. With this knowledge agencies working with refugees can focus resources where they can have the greatest impact. Some program enhancements could include: Psycho-social education for the losses associated with acculturation, group activities that enhance self-efficacy, recognition of the unique needs of men during this period and measures that reduce the impact of problems in the early months after resettlement. 


\section{TABLE OF CONTENTS}

PAGE

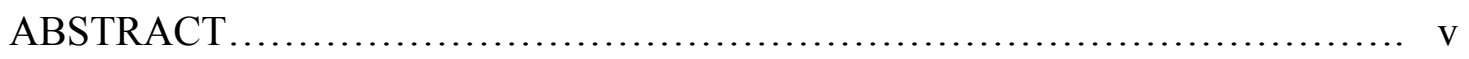

LIST OF TABLES............................................................................ xii

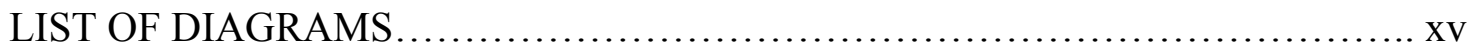

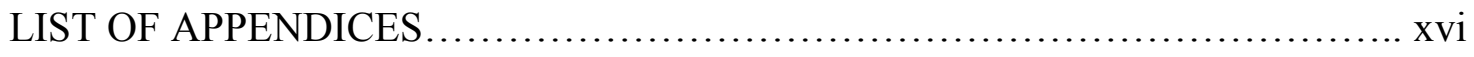

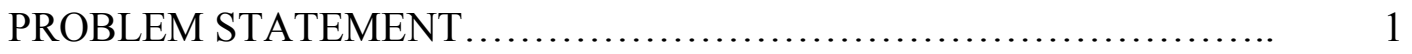

Introduction.................................................. 1

The process of qualifying as a refugee....................... 1

The US process for resettlement.............................. 2

The US program focus...................................... 3

The Problem......................................................... 4

Refugee capacity.......................................... 5

The psycho-social impact of the refugee experience............. 5

Premigration ........................................... 5

Post migration....................................... 6

Post adaptation of refugees........................... 7

Trauma and the link to emotional distress................ 8

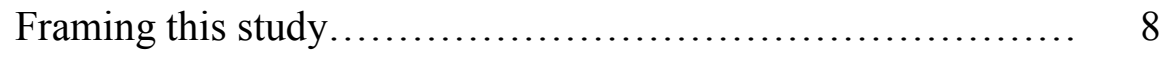

Importance for social work ...................................... 8

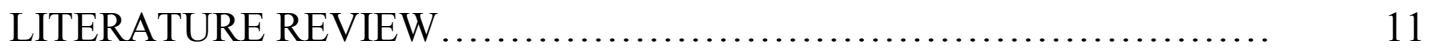

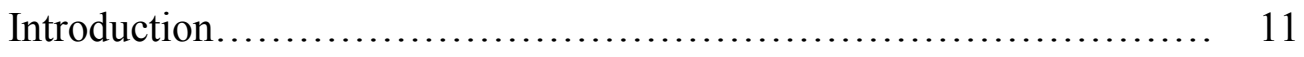

Theoretical foundation for a model of refugee migratory adaptation...... 11 
Stress and adaptation

Coping.................................................... 13

Appraisal............................................. 13

Adaptive resilience...................................... 13

Refugee resilience..................................... 14

Predictor Variables........................................... 15

Prearrival characteristics.................................. 15

Country of Origin..$\ldots \ldots \ldots \ldots \ldots \ldots \ldots \ldots \ldots \ldots \ldots \ldots \ldots \ldots$

Gender......................................... 16

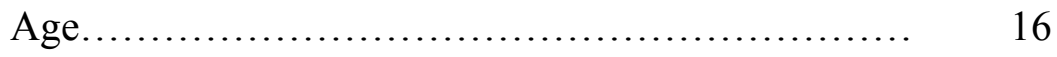

Number of prearrival traumas................... 16

Prearrival living location .......................... 17

Self-efficacy............................... 17

Self-efficacy and stress...................... 18

The study of self efficacy among refugees....... 19

Post arrival perceptions.................................... 19

Conservation of resources........................... 19

COR and stress........................... 20

The study of COR in refugees $\ldots \ldots \ldots \ldots \ldots \ldots \ldots \ldots \ldots .20$

Postarrival living problems........................ 20

Outcome variables.............................................. 21

Stress and emotional distress............................ 21

Refugee emotional distress............................... 21 
Summary and call for further research. ...

Research questions........................................... 23

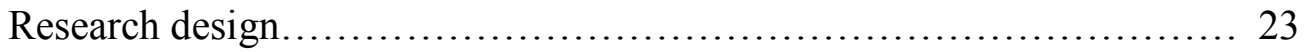

Sample selection.......................................... 23

Refugees from Burma.......................................... 25

Burmese resettlement.................................... 26

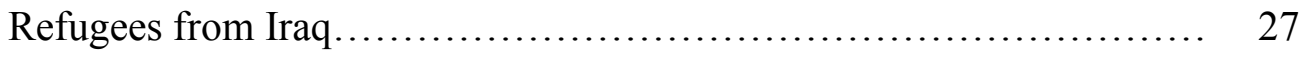

Iraqi resettlement...................................... 28

Refugees from Nepal....................................... 29

Nepali resettlement................................... 30

Ethical considerations and consent procedures.................... 30

Measures....................................................... 31

Predictor Variables...................................... 32

Demographic characteristics..................... 32

Prearrival traumas............................... 32

Post arrival living problems $\ldots \ldots \ldots \ldots \ldots \ldots \ldots \ldots \ldots \ldots \ldots \ldots \ldots$

Resource gain and loss $\ldots \ldots \ldots \ldots \ldots \ldots \ldots \ldots \ldots \ldots \ldots . \ldots \ldots$

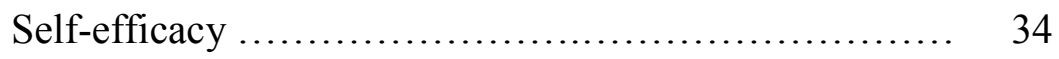

Outcome/Criterion Variable..................................... 35

Emotional distress (anxiety and depression)........... 35

Instrument preparation...................................................... 37

Data collection and management................................... 37 
Analysis..................................................... 38

RESULTS......................................................... 40

The data...................................................... 40

Cleaning and preparation of the data..................... 40

Collinearity.......................................... 41

Power................................................ 41

Model of analysis..................................... 42

Description of the sample....................................... 43

Demographic characteristics overview....................... 43

Demographics by country of origin $\ldots \ldots \ldots \ldots \ldots \ldots \ldots \ldots \ldots \ldots, 44$

Country of origin and ethnic group...................... 44

Gender.............................................. 45

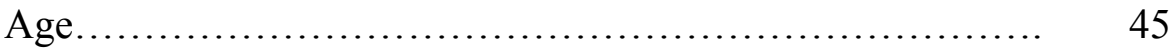

Prearrival living situation.............................. 46

Predictor variable outcomes.................................. 46

Predictor variable results by country of origin................. 47

Number of prearrival traumas........................... 47

Self-efficacy....................................... 48

COR gains and losses................................. 48

Number of post arrival problems ......................... 49

Emotional distress...................................... 50

Country of origin profiles................................... 50

Burma.............................................. 50 
Nepal.

Analysis

Research question 1

Anxiety

Depression.

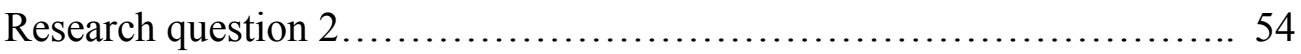

Anxiety. 54

Depression............................................. 55

Analysis of overall factors..................................... 56

Anxiety................................................... 57

Depression............................................ 58

Synthesis of results....................................... 59

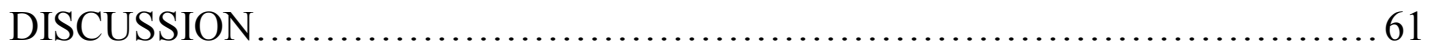

Method.................................................. 61

Summary of findings......................................... 61

Primary findings of the study............................ 62

Self-efficacy................................ 62

Resource loss...................................... 63

Gender....................................... 64

Prearrival traumas................................. 64

Post arrival problems............................... 65

Contribution of the study................................ 65 
Implications for social work............................... 65

Considerations for practice................................. 66

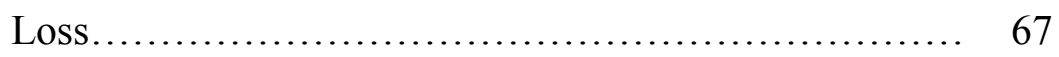

Building self-efficacy........................... 69

Problems after migration.......................... 69

Resettlement program.......................... 70

Considerations for policy............................. 71

Considerations for research............................ 72

Strengths of the study......................................... 72

Limitations of the study...................................... 73

Conclusion....................................................... 74

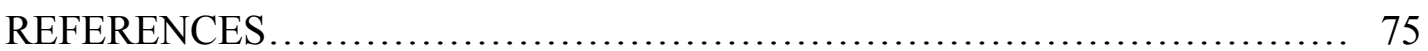

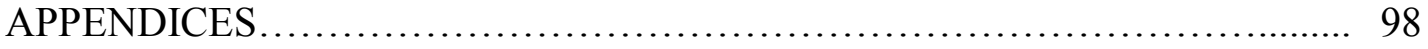

CURRICULUM VITAE................................................... 111 


\section{LIST OF TABLES}

TABLE

PAGE

1. Variables by Instrument.................................... 31

2. Percentage of Missing Items by Instrument........................ 41

3. Frequencies of Prearrival Characteristics......................... 43

4. Ethnicity by Country of Origin............................... 44

5. Frequencies of Gender by Country of Origin....................... 45

6. Age by Country of Origin..................................... 46

7. Living Location Prior to Resettlement by Country of Origin........... 46

8. Description of Predictor and Outcome Variables...................... 47

9. Prearrival Traumas by Country of Origin....................... 47

10. Self-Efficacy by Country of Origin.............................. 48

11. Resource Gains and Losses by Country of Origin.......................... 49

12. Post Arrival Problems by Country of Origin........................... 49

13. Anxiety and Depression by Country of Origin.................. 50

14. Logistic Regression Results- Prearrival Characteristics.............. 53

15. Logistic Regression Results-Postarrival Perceptions.................. 56

16. Logistic Regression Results of Overall Factors...................... 59 


\section{LIST OF DIAGRAMS}

1. Sampling Process.................................................. 25 


\section{LIST OF APPENDIXES}

APPENDIX $\quad$ PAGE

1. Basic Health Information.......................................... 98

2. Comprehensive Trauma Inventory-Short Form $12 \ldots \ldots \ldots \ldots \ldots \ldots \ldots \ldots \ldots . . . \ldots 9$

3. Generalized Self-efficacy Scale ...................................... 100

4. Hopkins Symptom Checklist-25..................................... 101

5. Post Migration Living Problems....................................... 104

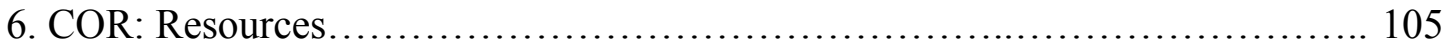


CHAPTER 1

PROBLEM STATEMENT

\section{“I have crossed so many rivers, I no longer get wet” (Kurdish adage) Introduction}

First defined by the Convention and Protocol Relating to the Status of Refugees in 1951, a refugee is someone who, "owing to a well-founded fear of being persecuted for reasons of race, religion, nationality, membership of a particular social group or political opinion, is outside the country of his nationality, and is unable to, or owing to such fear, is unwilling to avail himself of the protection of that country" (United Nations High Commission on Refugees, 2011, p. 14). More than 100,000 refugees, asylees and special visa holders were resettled in the United States in 2012 (United States Department of Health and Human Services, 2012). After completing an arduous process to qualify, most refugees arrive to the United States with great hope for the future. Many, however, find their new life overshadowed by the challenges of adaptation, making the long awaited end to their journey appear out of reach.

\section{The process of qualifying as a refugee}

The United Nations High Commission on Refugees, (UNHCR) is tasked with the oversight of refugees worldwide. In 2011, more than 800,000 people were newly displaced due to conflict or persecution as refugees across international borders, the highest number in more than a decade (UNHCR, 2011). The process of qualifying as a 
refugee begins with documentation of the individual's situation, and includes repeated interviews requiring persistence and consistency (UNHCR, 2011). The protocol requires each applicant to provide a detailed history of events leading up to their application that includes the reason for displacement. The refugee application guidelines clearly state that the burden of proof lies with the person making the claim.

\section{The United States process for resettlement}

Each year after consulting with Congress and the appropriate agencies, the President of the United States designates the processing priorities for refugee resettlement for the upcoming year. Between 1975 and 2005, the United States resettled over 3 million refugees (Corvo \& Peterson, 2005). Despite the September 11, 2001 backlash against foreigners entering the US, resettlement efforts continued with the US admitting more than twice the number of refugees than all other nine countries in the program combined (Vissicaro, 2009).

As a federal agency of the United States Department of Health and Human Services (USDHHS), the Office of Refugee Resettlement (ORR) manages the process of resettlement through nine domestic voluntary agencies. In 2012, the ORR provided services to more than 115,000 new arrivals from more than 85 countries. These figures include over 62,000 refugees and Special Immigrant Visa holders, more than 40,000 asylees and Cuban/Haitian Entrants and Parolees, and a significant number of Unaccompanied Alien Children. The highest number of arrivals originated from Nepal $(15,000)$ and Burma $(14,000)$ comprising more than half of all arrivals, followed by refugees from Cuba, Iraq, Somalia, the Democratic Republic of Congo, Iran, Eritrea, Sudan, and Ethiopia (USDHHS, 2012). Refugees arrive in the United States as legally 
documented immigrants, but citizenship is not guaranteed, and must be obtained through a variety of steps taken over the next 5 to 7 years.

The US program focus. Under the direction of the United States State Department, and under the provisions of Title IV of the Immigration and Nationality Act, ORR is to provide for the effective resettlement of refugees and to assist them to achieve economic self-sufficiency as quickly as possible. Title IV directs each state to ensure that language training and employment services are made available to refugees. In addition, states are to provide cash assistance and a medical assistance program that includes a medical screening within the first 90 days after arrival. The local resettlement agency is required to provide the basic support for housing set-up, English classes, and job placement assistance.

The local resettlement agency receives financial incentives from ORR for employment outcomes. Beyond these initial services, the only program assistance guaranteed to refugees is support with employment for up to five years after arrival. Previously deemed a humanitarian program, recent economic changes in the US have led to shifts in national priorities placing more emphasis on employment leaving fewer resources for mental health (Luta Garbat-Welch, personal communication, March 27, 2013). Even after fulfilling the expectations of the employment focused resettlement process many refugees are left in low paying jobs without health insurance and no safety net (Lacroix \& Sabbah, 2011; Weine, et al., 2008).

ORR protocol lacks guidance for local programs on the handling of refugees with greater medical and mental health needs and agencies are simply encouraged to seek services without clear definitions, protocol or funding (Vissicaro, 2009). This approach 
may be adequate for refugees who are struggling only with adjustment stress within normal limits (Miller \& Rasmussen, 2009); however, more services are clearly indicated for those with serious mental illness (Weine, 2011).

\section{The Problem}

Current US resettlement policy standards and program designs do not take into consideration the impact of specific factors that challenge a refugee's capacity to adapt during the first few months of resettlement. One reason is that there are varying perspectives on what contributes to healthy resettlement for refugees (Yakushko, 2010) and more needs to be understood about what specific factors have an impact on refugees during resettlement (Hooberman, Rosenfeld, Rasmussen, \& Keller, 2010; Overland, 2011). A variety of studies have explored factors that may improve refugee functioning concluding that there are many possible combinations that impact migration adaptation (Beckerman \& Corbett 2008; Colic-Peisker \& Walker, 2003; Corvo \& Peterson, 2005; Miller et al., 2006; Mui \& Kang, 2006; Oh, Koeske, \& Sales, 2002) often with conflicting results. With limited resources, clearer identification of the factors that support migration adaptation and contribute to achieving overall well-being are critical to the focused development of resettlement policy and programs.

US resettlement protocol places significant demands on the refugee in the early stage of migration. Refugee ability to adapt is an interaction between past experiences, personal characteristics, and the daily obstacles they encounter in resettlement. Below is an overview of the elements each refugee brings to the early stage of migration and the challenges that occur during the first few months in the period of resettlement.

\section{Refugee capacity}


Refugee capacity has been defined as the refugee's ability to integrate, or adapt at least on some level, into life in the country of resettlement (Ager \& Strang, 2008; Ryan, Dooley, \& Benson, 2008). After enduring years of living with uncertainty, the difficulty of integration into the new culture can be a shock to those refugees expecting relief (Weine et al., 2002). The refugee is challenged to make the changes necessary to integrate thereby creating a particular form of stress that can manifest in emotional instability, diminished self-worth, shifting role and relationship dynamics, lack of safety and limited control (George, 2012; Jamil et al., 2007; Momartin, Silove, Manicavasagar, $\&$ Steel, 2004). Refugees often experience high levels of physical and emotional distress upon arrival to the country of resettlement (Hollifield et al., 2006; Mollica, 2006). In spite of these challenges, most refugees manage the stresses of adjustment, find employment, care for their families and recover from past trauma.

The psycho-social impact of the refugee experience. By definition, a refugee is someone who has fled his or her homeland and undergone a series of challenging events (UNHCR, 2012). Models that have attempted to define the effects that accompany this experience vary in emphasis but agree that transition, loss, and self-perception are at the core of the stress on refugees (Berry, Kim, Minde, \& Mok, 1987; Colic-Peisker \& Walker, 2003; Dow, 2013; Drachman, 1992). While each refugee experience varies there are some common themes that can be identified.

Premigration. The refugee experience begins with an inciting traumatic event (Berry et al., 1987) that represents a threat to life, safety, family, or community (Mollica et al., 1992). The challenges of the premigration stage include the economic, social, and political impacts that led to the refugee's departure from a homeland as well as the 
context within which the refugee lived prior to the inciting traumatic event (Drachman, 1992). Bhugra (2004) agreed that these preexisting elements are highly significant to the ultimate adjustment in resettlement.

According to Lacroix and Sabbah (2011), refugees have been exposed to increasingly violent situations often involving neighbor-on-neighbor attacks that leave whole communities displaced and desperate. For many, it also includes brutal treatment or systematic torture at the hands of individuals representing oppressive political or social regimes (Potcky-Tripdi, 2003). Individuals flee from life-threatening circumstances without considering that they may never return (Drachman, 1992). Family members are often separated and must make decisions about who travels with whom, what direction to travel and who is left behind (Weine et al., 2002).

After fleeing danger, many refugees are forced to live in substandard conditions in refugee camps or other inadequate living situations where medical care and food supplies are limited and survival often depends upon competition for resources (ColicPeisker \& Walker, 2003). In this time of uncertainty, refugees endure separation from family members, their home country, culture and language of origin (Keller et al., 2006). Refugees endure limited choices, little power, and unresolved trauma, creating a diminished sense of safety, disruption of normal relationships and a complex destruction of the social fabric (Casado, Hong, \& Harrington, 2010).

Postmigration. A significant barrier to healthy resettlement is the discrepancy between the refugee's expectations and the reality of life in the new location (Drachman, 1992). This factor of individual perception plays a vital role in the refugee's capacity to adjust to the changes in lifestyle, priorities, expectations, social roles, and language use 
(Weine et al., 2008). Along with the social and psychological challenges of this period, the refugee may experience increased anxiety about achieving the expectations placed by the U.S program agency (Casado et al., 2010).

The dynamic process of adaptation requires the individual to learn new behaviors and take risks (Berry, 2001) often creating interpersonal conflict within families and groups (Nicholl \& Thompson, 2004). The transition creates a reduced sense of capacity, challenges emotional resources, and can further isolate the refugee psychologically (Berry, 2001). For some refugees this process creates self-doubt, particularly in the early months of resettlement, leading to limiting fears (Beckerman \& Corbett, 2008).

\section{Postmigration adaptation of refugees}

The psycho-social phenomenon of post migration adaptation of refugees is a multi-faceted process that occurs over time (Bhugra, 2004). The adaptation of an individual refugee is impacted by a variety of factors and can include: characteristics of the person, events that occurred in the past, the length of time in the period of limbo before resettlement, the refugee's cultural framework, and the receptivity of the resettlement country (Ager \& Strang, 2008; Colic-Peisker \& Walker, 2003; Ryan et al., 2008). Ultimately, for many refugees the stress of migration reactivates the autonomic nervous system response that was embedded by historical trauma, causing emotional distress (Yakushko, 2010).

Trauma and the link to emotional distress. The study of migration effects on refugees has been primarily focused on the psychological impact of historical trauma (Ager \& Strang, 2008), leaving other critical elements out of the equation. At the same time, the majority of refugees suffer significant symptoms of distress, and a large 
minority has diagnosable psychiatric disorders (Hollifield et al., 2013). Recognizing that refugees with psychiatric symptoms are at high risk if they do not receive services (Weine et al., 2008), it is important to have an expanded understanding of the factors contributing to or reducing emotional distress.

\section{Framing this study}

The unique aspects of the refugee experience requires that a comprehensive theoretical foundation be built on knowledge that accounts for the factors that contribute to adaptation for some and loss of capacity in others. This study looks at three distinct groups of refugees in an effort to identify the relationship between prearrival characteristics, postarrival perceptions, and emotional distress of refugees at the period just following migration in an effort to understand which of them may best support healthy adaptation.

This study builds on existing literature and measures the predictability of emotional distress based on a broad group of factors that include refugee demographics, living location prior to resettlement, prearrival traumatic experiences, self-efficacy, perceived resource gain and loss, and postarrival problems. Understanding the relationship between these factors is crucial to responding to the needs of newly arrived refugees and to developing programs that support improved functioning.

\section{Importance for social work}

According to the Council on Social Work Education, it is the role of the social work practitioner to promote wellbeing by identifying client capacity as well as dynamics of risk (Greene, Galambos \& Lee, 2003). However, the rapidly growing numbers of refugees in the US has exceeded the preparation of social workers (Corvo \& Peterson, 
2005). Arriving daily to resettlement agencies across the country are highly traumatized individuals with a need for more focused care (L. Kaznak, personal communication, January 24, 2013). The policy argument of whether the US resettlement program should focus on swift employment becomes irrelevant as refugees suffer without the services they need to address the symptoms causing increased disabling conditions (Weine et al., 2008). Agencies faced with diminishing funds for the basic resettlement of refugees are struggling to accurately identify the best way to focus resources (D. Mikhalovic, personal communication, January 26, 2013).

A comprehensive understanding of the refugee experience and its impact is necessary for social work and social work education to move into the future (Cassado et al., 2010). Efforts must be made to develop practice models that strengthen engagement with refugee communities and enhance refugee functioning ( $\mathrm{Lu}, \mathrm{Lum}$, and Chen, 2001). Understanding the common experiences, losses and challenges of transition through the refugee journey will enable social workers to assess areas of need more effectively.

In addition to understanding the bio-psycho-social issues faced by refugees, it is critical that the development of cultural competency skills are embedded into social work curriculum. Social worker knowledge must go beyond the general elements of client culture (Tseng, 2004) and include building capacity and skill in engaging cultural frameworks beyond our own.

A greater understanding of the challenges and strengths that impact refugees in the critical period of migratory adaptation is essential to the ongoing development of social work practice. Improving the evidence-based knowledge of this period will 
enhance our capacity to respond and develop programs for the ever-growing numbers of refugees arriving to the US seeking to fulfill their potential. 
CHAPTER 2

\section{LITERATURE REVIEW}

\section{Introduction}

This chapter begins with an introduction of a model of refugee migratory adaptation as the theoretical foundation for the study. It continues with a discussion of the research variables identified in the literature. This review informed the selection of variables that appeared to have potential to predict emotional distress in refugees. The variables have been categorized into two sets, refugee characteristics prior to migration and perceptions of refugees postmigration. Prearrival Characteristics includes Country of Origin, Gender, Age, Prearrival Living Location, Number of Prearrival Traumas, and Self-efficacy. Postarrival Perceptions includes Conservation of Resources, (Gains and Losses), and Number of Postarrival Problems. These sets of variables will be analyzed in relation to Anxiety and Depression. The literature presented below relies on published materials in English primarily located using the search sources in EBSCO, Social Work Abstracts Plus, PsychINFO, (EBSCOhost) and PsychINFO (Ovid). Search terms included: refugee(s), immigrant(s), refugee stress, self-efficacy, conservation of resources, adaptation, resilience, coping, functioning, acculturation, acculturative stress, mental health, migration, emotional distress and regression.

\section{Theoretical foundation for a model of refugee migratory adaptation}


Refugee migration adaptation is best defined as the process through which a person reorganizes their internal perspectives and external capacity in order to manage in a new sociocultural context (Ryan et al., 2008). Existing perspectives on the adaptation of refugees include sociocultural models, identity models, and economic models. A significant amount of related literature focuses on trauma as a key aspect, and while this is an important element, trauma alone does not account for refugee adaptation (Weine, 2001). Therefore, this study integrates multiple theories to explain the assumptions used in this research study.

This study draws on the theoretical contributions of a variety of scholars with emphasis on Maslow (1954), Lazarus and Folkman (1987), Hobfoll (1989), and Bandura (1998) in understanding human responses to stressful life events. Using these theories as a lens, this literature review will discuss the process of refugee adaptation following migration. The literature review continues with an overview of research on selected study variables and the questions posed in this study.

\section{Stress and adaptation}

The stress response is activated by situational changes that threaten human needs causing the individual to divert energy to restoring those resources (Maslow, 1963). Kaplan (1983) defined stress as the individual's reflection on their inability to diminish the perception or anticipation of a devaluing circumstance. Lazarus and Folkman (1984) asserted that stress is a measure of the individual's perceived capacity to access resources to respond to challenges. These definitions acknowledge that the readjustment necessary to return to the prechallenge state requires energy and focus that also increases stress for the individual (Pearlin et al., 1981). When this response system is over stimulated, it is 
described as emotional distress (van de Kolk, McFarlane, \& Weisaeth, 1996). In contrast to emotional distress, psycho-social functioning is defined as the ability to manage affect, especially anxiety and depression (Bandura et al., 2003).

\section{Coping}

The human stress response activates the individual's psychological and social resources creating an adaptive process (Hobfoll, 1989). This process, known as coping, has been described in numerous ways depending upon the researcher's perspective (Greene et al., 2003). This self-righting capacity occurs in the adaptation process and is related to the individuals' self-esteem (Pearlin et al., 1981). Hobfoll (1989) stated that this process leads to a conservation of resources as the means for the individual to evaluate and respond to the stressful situation.

\section{Appraisal}

The social cognitive model of stress suggests that in addition to coping, another construct of the stress response is appraisal (Lazarus \& Folkman, 1987). Referred to as resilience coping (Greene et al., 2003) appraisal explains the process of learned changes that accompany repeated stresses incorporating self-appraisal and a person's natural capacity to heal (Bandura, 1988). While stress resiliency does not have one clear or precise definition, the most common element of the construct includes the ability to overcome and is often defined as an adaptation response to high risk (Greene et al., 2003).

\section{Adaptive resilience}

The individual manages resources (Hobfoll, 1989) motivated by the desire for survival (Strumpfer, 2002) and develops behaviors that are self-protective leading to 
adaptive resilience (Greene, 2002). Resilience is more than survival and is defined as "the unpredicted or markedly successful adaptation to negative life events, trauma, stress, and other forms of risk" (Fraser, 1999, p. 136). Resiliency can also be defined as the recovery of the individual to the patterns of capacity they possessed before the episode of stress (Fong \& Greene, 2009). Stress, like that described above in the refugee experience, is a response to the loss of resources as individuals attempt to maintain or restore them (Hobfoll, 2002). Repeated loss, including threat to basic needs, leads the person through a process of self-appraisal, questioning one's capacity to survive (Bandura, 1988). It is suggested that in some cases the repeated process of self-appraisal can lead to perceptions of improved capacity (Lazarus \& Folkman, 1987).

\section{Refugee resilience}

The process of gaining refugee status prior to migration varies greatly among refugee populations. Depending on the level of stability and the social circumstances, the individual seeks to reestablish equilibrium using personal resources that may, in turn, lead them to becoming more vulnerable (Kaplan, 1970). In contrast, the individual may draw on mediating factors that enhance capacity (Pearlin et al., 1981).

The significant stress experienced by refugees at the time of resettlement can be explained by the assertion that when the two major sources of stress, the eventful experience and the role strain converge, they create the most significant stress (Pearlin et al., 1981). Coping therefore regulates emotional distress and activates the self-appraisal process, leading to new learning that may result in increased perceptions of capacity (Folkman \& Lazarus, 1986). Adaptive resilience is the outcome of developed coping and capacity in light of chronic threat (Greene et al., 2003). 
Ultimately, during the challenges of postmigration the refugee may draw on the previously developed coping resilience to achieve long-held goals. Or, some refugees may find that the previous loss of resources impedes them from accessing new resources made available during this period (Hobfoll, 1989). Linking these theories to the refugee experience, the individuals' appraisal of stress at resettlement is an example of the stress cycle feedback that leaves some refugees with a sense of capacity and others without (Yakushko, 2010).

\section{Predictor Variables}

\section{Prearrival characteristics}

Country of Origin. Self-perception, and therefore sense of identity, is impacted by individual, social and cultural standards that are often difficult to separate from the psychological response to trauma (van de Kolk et al., 2005). The manner in which the individual describes the physiological reaction varies by the person's worldview, cultural framework, or social situation (Kohrt \& Hruschka, 2010). Therefore, within language or culture groups, there are discernable patterns that arise, especially in response to shared events like large-scale war or war-like situations (Lacroix \& Sabbah, 2011).

Events that occur over time in a person's life initiate new patterns of behaving, creating changed perspectives (Potcky-Tripdi, 2003). The impact of the repeated traumatic events and periods of transition create shifting social attitudes through which group behaviors are normed (Walter, Horsey, Palmieri, \& Hobfoll, 2010). In refugee resettlement these changes in norms combine with the receptivity and expectations of the host country creating social group behavioral patterns (Colic-Peisker \& Walker, 2003). 
Gender. The impact of shifting expectations of women creates greater vulnerability for female refugees (Yohani \& Hagen, 2010). Porter and Haslam (2005) identified that female refugees have worse resettlement outcomes than males, a notion supported by Schweitzer, Melville, Steel and Lacherez (2006) in a study of Sudanese in Australia; and by Lavik, Hauff, and Solberg (1999) in a study of refugees from five continents. Research with Bosnian refugees had varying outcomes, one finding that gender was not significant (Knipsheer \& Kleber, 2006) and another suggesting females had only mildly greater vulnerability than males (Momartin et al., 2004).

Age. Several studies suggest that older refugees have worse outcomes than younger refugees (Brown, Schale \& Nilsson, 2010; Porter \& Haslam, 2005). A study of Holocaust survivors suggests that older survivors of trauma have increased emotional distress than younger survivors (Dekel \& Hobfoll, 2007). In contrast, a study of Bosnian refugees (Knipsheer \& Kleber, 2006) and a study of male refugee survivors of torture (Carlsson, Mortensen \& Kastrup, 2006) found that age had no correlation to emotional distress.

Number of prearrival traumas. Research indicates that refugees have higher rates of trauma-related disorders and somatization than the general population or other immigrant groups (Hollifield et al., 2002; Kilpatrick et al., 2011; Littleton et al., 2011) with some reporting that the rates of symptoms of emotional distress among refugees are significant (Palik \& Elklit, 2011). Symptoms of anxiety, depression, and somatic complaints are a result of severe or repeated traumatic experiences in the refugee's past (Mollica et al., 1992; Momartin et al., 2004; Schweitzer, Brough, Vromans \& Asic-Kobe, 2006). The refugee experience has long-term effects and is often defined as a chronic 
illness based on a series of significant, often catastrophic events (Keller et al., 2006; Kiezler, 2008; Mollica, 2006; Nickerson et al., 1998), and can create major shifts in psychological wellness and negative health factors in entire groups of people (Hollifield et al., 2002).

Prearrival Living Location. A unique aspect of the refugee experience is the forced migration to a secondary location while awaiting refugee status. Although no literature was found for this review that discusses the impact of the living locations for refugees during that period of time, this study will look at the impact of living in a camp, staying in the home country, or living in another setting.

Self-efficacy. Self-efficacy is based in social cognitive theory (Bandura, 1988) and is understood as a mechanism of human agency (Bandura, 1989). A core of human functioning, self-efficacy is defined as an individual's perception of function and capacity to impact their environment (Bandura, 1989; Schwarzer, Jerusalem, \& Hahn, 1994). Selfefficacy is grounded in a person's belief in the possession of power to create desired effects (Bandura, 1997). Personal efficacy is centered in the knowledge that one has power to reach identified outcomes and the capacity to execute a course of action that leads to attainment of a desired goal (Bandura, 1997).

Self-efficacy regulates the cognitive, motivation, affect, and decision-making processes (Benight \& Bandura, 2004). Understood as an individual's cognitive perception of competence (Hughes, Galbraith, \& White 2011), self-efficacy includes optimism, response to adversity, persistence, goal setting, and investment of effort and is a key component of the individual's perceived assessment of capacity in the face of challenge (Bandura, 1989). 
Self-efficacy asserts that a continual social cognitive process of self-assessment leads to transformation of thoughts into action ultimately producing personal appraisal judgments (Benight \& Bandura, 2004). Accurate self-knowledge and appraisal is the key to social identity and functioning (Bandura, Caprara, Barbaraelli, Gerbino \& Pastorelli, 2003). Self-efficacy is affected by experiences both negative and positive (Hughes et al., 2011) leading to an individual's possession of confidence to complete tasks (Benight \& Bandura, 2004).

Self-efficacy and stress. Self-efficacy is a central component in the quality of coping in stressful situations (Bandura, 1997). Operationalized, self-efficacy is linked to stress-related behaviors and is based in self-beliefs that are in opposition to those that are generated in the human response to trauma (Schwarzer \& Jerusalem, 1995). It is asserted that self-efficacy is grounded in the logical learning centers of the brain, the same areas that are diminished in the stimulation of the stress response (van de Kolk, 1996). The parasympathetic system creates chemical and physical changes overriding cognitive brain activity (Bremner, 2005). Research into this process occurring in the brain suggests that traumatic events generally diminish the reported sense of competence (Bandura et al., 2003). Self-efficacy is viewed as a critical aspect of perceived coping after a traumatic event (Benight \& Bandura, 2004). It has been suggested that reoccurring symptoms of traumatic stress reflect directly on the individual's perceived sense of functioning (van de Kolk et al., 1996). Bandura (2003) states that psychosocial functioning is directed by perceived self-efficacy including the capacity for affective self-regulation linked to the socialization process and supported by social forces. 
The study of self-efficacy among refugees. The relationship between refugee trauma, functioning and self-efficacy has received increased attention from researchers over the last decade. There is limited documented research on self-efficacy with refugee populations with contradictory findings being reported. Below are the results of some of those studies.

Ferren (1999) studied the relationship between symptoms of PTSD and selfefficacy in Bosnian and Croatian adolescents concluding that the adolescents with symptoms of stress had higher levels of self-efficacy than those who did not have symptoms. And, although there were no significant differences among females, the selfefficacy of the males who had not been traumatized was significantly lower than the traumatized males (Ferren, 1999). In a study of Afghani refugees, Sulaiman-Hill and Thompson (2013) explored the relationship between self-efficacy and symptoms of stress. Consistent with the Ferren study, Sulaiman-Hill and Thompson concluded that there was a significant relationship between self-efficacy and lower levels of distress. However, a third study of refugees and self-efficacy comparing Vietnamese refugee youth who resided outside of Vietnam to those who never left Vietnam concluded that the self-efficacy of the two groups did not differ significantly (Loughry \& Flouri, 2001).

\section{Postarrival perceptions}

Conservation of resources. Conservation of resources (COR) theory is based in social psychology and was developed as an alternative model for explaining the human response to stress and focuses on an individual's perception of resources gained and lost (Hobfoll, 1989). Hobfoll (1989) stated that the basic tenant of COR theory is that individuals are motivated to retain, protect, and build on their resources, and threat is 
defined as the potential for loss of the things that are valued. Hobfoll (1989) identifies five domains in the model including object resources, valued conditions, personal characteristics, energies, and social support. Hobfoll (2002) asserts that COR theory recognizes the central sociocultural aspects affecting an individual's evaluation of a stressful situation and purports that resource gain and positive emotions are of primary importance in response to trauma (Hobfoll, 2001).

COR and stress. Hobfoll (1989), in defining COR theory, tied resource loss directly to stress suggesting that the greater the resource loss the greater the challenge to return to the pretrauma state. Trauma leads to a reduction of resources limiting the person's ability to regain those that were lost (Hobfoll, 2001; Hobfoll \& Lilly, 1993). This process has the potential to increase symptoms of depression (Hobfoll et al. 1991). Resource loss is a critical aspect of traumatic stress and the capacity for resource development can increase one's ability to manage life's stressful situations (Hobfoll, 2003).

The study of COR in refugees. Loss of resources is a central construct to refugee trauma, although no research measuring COR with refugees could be located for this review. However, Dekel and Hobfoll (2007) measured COR in Holocaust survivors living in Israel during a period of war-like conflict. The study concluded that the Holocaust survivors had higher levels of emotional distress than those Israelis without a history of significant trauma drawing a positive correlation between traumatic experience and increased loss of resources (Dekel \& Hobfoll, 2007).

Postarrival living problems. Multiple studies confirm the supposition that fewer postmigration problems are a key element to improved refugee functioning (Aragona et 
al., 2011; Hodes, Jagdev, Chandra, \& Cunniff, 2008; Hooberman et al., 2010; Lie, 2000; Schwarzer et al., 1994). Multiple studies indicate that the presence of postmigration problems is a factor in reported symptoms of emotional distress (Schweitzer et al., 2006; Teodorescu et al., 2012; Wessels \& Kostelny, 2012). Additional studies have indicated that reducing postmigration challenges for refugees is an important factor in improving wellbeing and reducing symptoms of emotional distress (Dalgard et al., 2006;

Hooberman et al., 2010; Knipsheer \& Kleber, 2006; Momartin et al., 2003; Sossou, Craig, Ogren, \& Schnak, 2011; Vonage et al., 2010).

\section{Outcome variables}

\section{Stress and emotional distress}

Pearlin et al. (1981) defined stress as the impact on the individual of the attempt to return to homeostasis as a consequence of discrete events or continuous challenges. Inner perceptions of self provide support for healing and determine functioning during periods of stress (Briere \& Scott, 2006). Multiple authors have asserted the connection between stress, traumatic events, self-perception, and functioning (Benight \& Bandura 2004; Bandura et al., 2003; Connor, 2006).

Refugee emotional distress. Many studies link refugee functioning and symptoms of emotional distress (Beckerman \& Corbett, 2008). Wessells and Kostelny (2012) identify anxiety and depression as key symptoms of emotional distress for individuals who have experienced forced migration. Whether looking at family adaptation (Renzaho, Green, Mellor, \& Swinburn, 2011) or adjustment of adolescent refugees (Hasanović \& Danas, 2012) functioning is measured by the capacity to manage and self-regulate emotions in social circumstances. 
A meta-analysis comparing factors of pre and postdisplacement impact on refugees reviewed data from 56 studies published between 1959 and 2002 and concluded that refugees had moderately poorer outcomes than non-refugees (Porter \& Haslam 2005). Another study that analyzed anxiety and depression in a convenience sample of refugees stated that $81 \%$ had clinically significant anxiety, $84 \%$ had clinically significant depressive symptoms and $45 \%$ had significant posttraumatic stress symptoms (Keller et al., 2006). In a systematic review of studies evaluating posttraumatic stress disorder in refugees the rates of the diagnosis in refugees range from 12 to $91 \%$ (Palic \& Elklit, 2011). The variation in the rates of emotional distress in refugees is, at least in part, due to a complex set of factors (Hooberman et al., 2010).

\section{Summary and call for further research}

Published studies exploring refugee adaptation is growing but limited as evidenced in the above review of the research literature. Although the variables that impact refugee capacity during this period have not been clearly identified in the empirical literature, important links between self-efficacy, conservation of resources, individual characteristics, past trauma, and refugee functioning are purported. Therefore, more research is needed in this area, particularly research that considers specific factors (Hodes et al., 2008). Increased understanding of the relationship between these constructs will enhance both assessment practices as well as treatment methods (Gillespie, Peltzer, \& Maclachlan, 2000), resulting in improved social work policy and models for practice. 


\section{CHAPTER 3}

\section{METHODOLOGY}

The purpose of this study is to identify the extent to which a set of prearrival characteristics and postarrival perceptions can predict refugee emotional distress during the early period of resettlement. The results of this exploratory study will provide an expanded foundation for this area of limited research.

\section{Research questions}

Question 1: To what extent do prearrival characteristics, (country of origin, gender, age, number of prearrival traumas, prearrival living location and self-efficacy), predict reported levels of emotional distress, (anxiety and depression), in recently arrived refugees?

Question 2: To what extent do postarrival perceptions, (conservation of resources, gained and lost, number of postmigration problems), predict reported levels of emotional distress, (anxiety and depression), in recently arrived refugees?

\section{Research Design}

An exploratory preexperimental, one-group design will be used to identify the relationship between demographic, prearrival characteristics, postarrival perceptions and emotional distress in refugees shortly after arrival to the US. The study analyzes secondary data from 170 refugees in the second and third month after arrival.

\section{Sample selection}


The sample was drawn from recently arrived refugees to Seattle, Washington. Recruitment of participants for the study occurred between April 2010 and November 2010 of refugees aged 14 and over who had been in the United States between 30 and 90 days.

Of the 493 refugees eligible to participate, 251 completed an initial set of inventories. No data was collected from the remaining 241 during the randomly sequenced data collection days either because there was no interpreter, no transportation or no screener available. One refugee declined to participate in the research. Refugees that arrived with a health status classification of psychosis were excluded prior to the sampling, eliminating two refugees (S. Verbillis-Kolp, personal communication, June 17, 2013).

The data used in this study are from a second set of inventories that was collected from 190 participants within one month of the initial set. This data were collected from refugees who remained in the area and were able to be located for the follow-up session. There was not a systematic recording of the reasons the remaining refugees were not scheduled however, 61 participants could not be included because the refugee moved away from the area, the refugee was not able to be reached at any address or telephone number on record, or the refugee declined due to scheduling conflicts (S. Verbillis-Kolp, personal communication, June 17, 2013). Due to the length of time necessary to complete the full battery of instruments, some refugees did not complete all inventories. For the purposes of this study the final data set of 170 cases includes those cases that had no more than one incomplete inventory. 
The data were collected by researchers at the Pathways to Wellness program. The research was funded by The Robert Wood Johnson Foundation, The Bill and Melinda Gates Foundation, United Way of King County, The Medina Foundation, The Seattle Foundation, and the Boeing Employees Community Fund. The table below outlines the sampling process that led to the final 170 refugee respondents in this study.

Diagram 1

Sampling Process

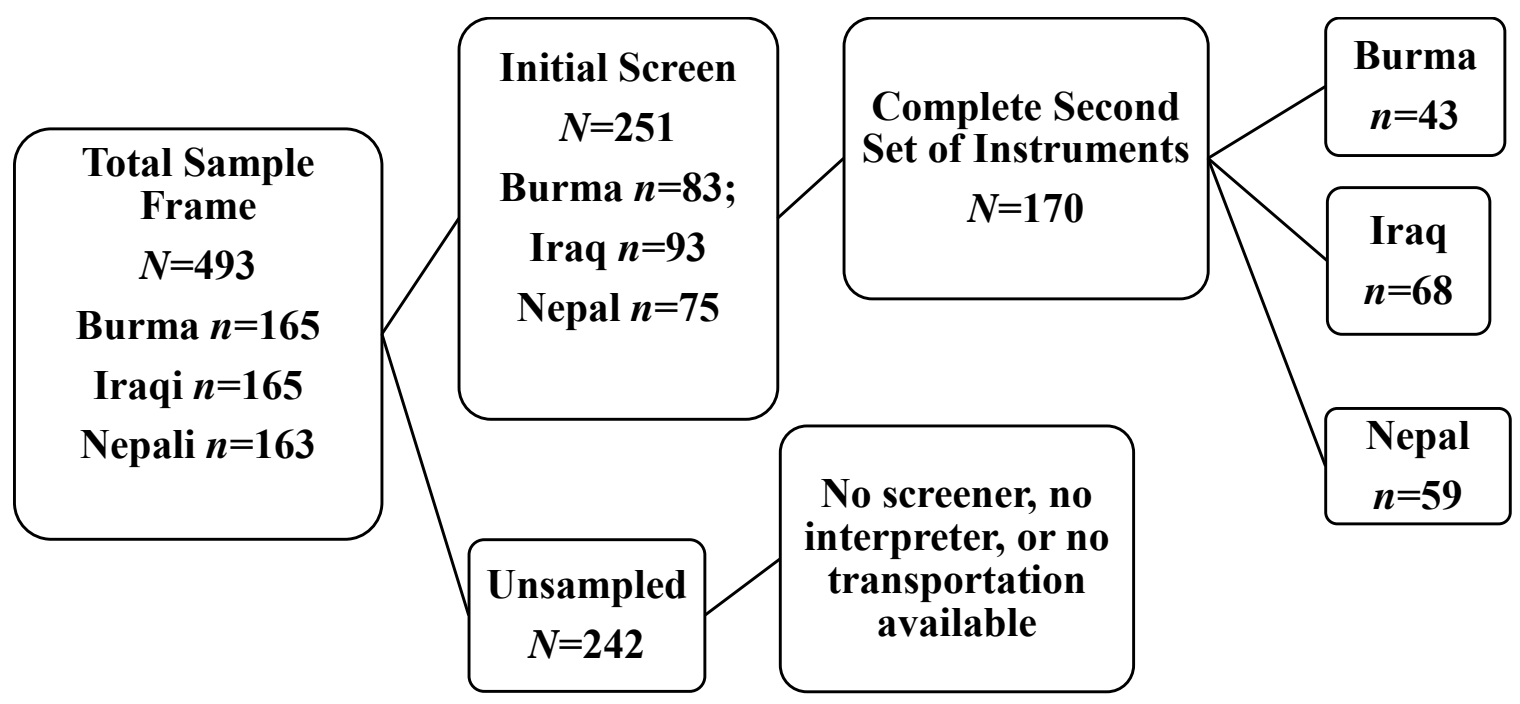

\section{Refugees from Burma}

Burma is the source of one of the most protracted refugee crises ever (UNHCR, 2012). Officially called the Union of Burma when it achieved independence from the United Kingdom in January of 1948, Burma has been under the Burmese military authority since 1962 when the group seized control. As the largest ethnic group in Burma, the Burman have attempted to keep the union together with military force while Karen and Karenni resistance groups have waged an ongoing war. The non-Burmese groups occupy $57 \%$ of the land mass and are $40 \%$ of the population. Projecting ethnic superiority, the Burman army maintains that they must protect national sovereignty by 
any means including the use of severe human rights violations. In 1989, the military government announced they wanted foreigners to stop using Burma as the name of the country and adopt the formal name of Myanmar. Many groups within the country objected to this change questioning the military's right to rule. In 1990 elections were held and the winners have never been allowed to take power (UNHCR, 2013).

Burma is one of the most ethnically diverse countries in the world. Within the eight main ethnic groups inhabiting the country, anthropologists have counted more than 130 distinctive subgroups. Their diversity is reflected in the rich range of color and design of dress, head wraps, and traditions. The vast majority of refugees from Burma are accustomed to an agriculture-based economy with the main staple of rice. Forced off their land refugees from Burma have lived in refugee camps for nearly a generation. The Burmese groups in the US represent a variety of religions including Buddhist, Islam, and Christian faiths (UNHCR, 2013).

Burmese Resettlement. Of the 16,693 Burmese refugees resettled in the US in 2010, the three main groups include the Burmans, the Karen and their various subgroups, and the Chin (USDHS, 2011). Most of the Karen and Burmans have been resettled from refugee camps in Thailand. Most of the Chin have been resettled from Malaysia where they resided illegally. Resettlement in the US has introduced Burmese groups to modern amenities that they lacked living in Burma and the Thailand camps. The Thai camp conditions are harsh by all accounts and stories told by refugees reflect a difficult life. Thai military patrol the camp borders in an effort to keep the refugees confined. Stories shared by Burmese refugees in the US after arrival indicates various forms of maltreatment common in the camps. Refugees from Burma report crossing landmine 
fields bordering the camp in an effort to earn money to provide for their families often resulting in severe injuries. Childhood education within the camps is optional and medical care and food supplies have been known to be limited.

The Burmese refugees in the US have struggled with adapting to modern technology, with many adults never having lived with running water or electricity, and never ridden a bus, or attended school. A minority of arrivals from Burma have ever driven a car. Education of children is a primary focus of parents who easily extend complete trust to educators regarding their children's needs (USDHS, 2011)

Burmese are considered mildly tempered, accepting of others, and highly compliant by resettlement staff. A significant number of refugees from Burma are known to use substances including areca or betel nut, alcohol, and other drugs that were available in Burma and Thailand, but illegal in the US (UNHCR, 2013).

\section{Refugees from Iraq}

The US military entered Iraq in early 2003, partly in response to the September 11, 2001 attacks. After Baghdad fell on April 12, a wave of looting and vandalism led to the plunder of many historical properties. The ruler at the time, Saddam Hussein, a Sunni, ruled a majority Shi'is country. Working with the Shi' is leaders, the US sought to ensure majority rule in Iraq and end the era of Sunni domination. The Iraqi army was dissolved, the Ba'th Party banned from participating in Iraq's government, and measures were made to privatize the economy (Ranard, 2008).

Since the invasion in 2003, Iraq has been plagued by the absence of law and order. The presence of Al-Qa'ida in Iraq has lead to suicide bombings and attacks on civilians. Shi'i militias infiltrated the newly created police and security forces and formed 
death squads that assassinated leaders of the Sunni insurgency as well as many innocent civilians.

The UNHCR estimates that more than four million Iraqis have been displaced by the war in Iraq and its aftermath. Meanwhile, general lawlessness and disruption of the economy continue to cause Iraqis to flee their homes. Today, an estimated two million Iraqis have taken refuge in neighboring countries, primarily in Syria and Jordan. Most Iraqi Arabs, Kurds, and Turkomen are Muslims, making Islam the religion of about 95\% of the country's population with Christians at 4-5\% of population (Ranard, 2008).

Iraqi Resettlement. During fiscal year 2010 a total of 18,016 Iraqi refugees arrived to the US and were resettled in every region of the United States (USSD, 2010). According to UNESCO, Iraq had one of the best educational systems in the Middle East before the 1991 Gulf War, with high levels of literacy for both men and women. Institutions of higher education were of an international standard, particularly in science and technology (Ranard, 2008).

Iraqi refugees bring considerable strengths and resources to the US. Iraqi refugees are considered generally knowledgeable about Western life, open-minded in their attitudes toward cultural differences, and resourceful. As a group, they often have more formal education, professional work experience, and English language skills than other refugee groups. Those who have joined the workforce have generally proven to be diligent and well-regarded employees (Ranard, 2008). And while Iraqis may find some American beliefs and behaviors confusing and even offensive, they generally respond positively to other aspects of American life (Ranard, 2008). For the most part, Iraqis 
admire American values of achievement, scientific progress, and freedom and equality (UNHCR, 2013).

One challenge facing the Iraqi refugees is the lack of employment opportunities equivalent to their prearrival professional status, especially if they have limited English skills. This also impacts their financial ability to maintain the lifestyle they had prior to arrival. This has often led to disappointment and frustration. Many who had high expectations for support during resettlement express distress when encountering US benefits and public assistance program support (UNHCR 2013).

\section{Refugees from Nepal}

The neighboring countries of Bhutan and Nepal have an intertwined history that began for the Bhutanese--or Nepali refugees-- around 1958 when a small group of Nepali families were invited into Bhutan to cultivate an underdeveloped region. Then in the mid 1980's after tightening it's citizenship laws, Bhutan held a special census and proceeded to force out almost 100,000 people. As Nepali community leaders attempted to accommodate the law by issuing certifications of residency and document past paid taxes, the Bhutanese government responded by imprisoning them. At this time, Bhutan's One nation, One people policy dictated the use of only one language, Dzongkha and one style of national dress. The Nepali language became outlawed in schools and many Nepali individuals lost jobs. During this period of military rule, Bhutanese Nepali's report stories of arrest, rape and torture. While some protested, others were forced to sign agreements to leave Bhutan. Many fled back to Nepal in 1990 and 1991. Those that passed through India were offered transport by the Indian government to ensure they did not remain in India (UNHCR, 2013). 
Nepali Resettlement. The acceptance rate of UNHCR's referrals in Nepal by resettlement countries is the highest in the world at 99.4 per cent of total submissions. The US, in close coordination with the International Organization for Migration (IOM), began resettling Bhutanese refugees residing in eastern Nepal in 2007. Of the original population of 108,000 refugees originating from Bhutan and living in Nepal, 12,363 arrived to the US in fiscal year 2010 (USSD, 2010). The Nepali refugees are a diverse group and represent several religions including Christianity, Hinduism, and Buddhism. All Bhutanese refugees speak Nepali and most speak at least some English (UNHCR, 2013).

One postresettlement concern related to Nepali refugees is the growing rate of suicide within the community. The CDC issued a report that estimated the annual suicide rate among Bhutanese refugees resettled in the US at 21.5 per 100,000 . This based on 16 reported suicides (four in 2009, six in 2010, five in 2011, and one as of February 2012).

The age-adjusted suicide rate using the U.S. 2000 population as the standard was 24.4 per 100,000 (CDC, 2013).

\section{Ethical considerations and consent procedures}

Refugees are considered a vulnerable population due to the distinct challenges of acculturation, and the lack of access to services, English language skills, and social capital. Prior to arrival to the United States, most refugees have experienced abuses of power, coercion, or persecution often leading to a fear of authority. Therefore, in many cases, it is difficult for recently resettled refugees to decline consent without fear of retaliation (Jacobsen \& Landau, 2003). Recognizing this vulnerability, considerations were made to ensure adherence to ethical standards. 
Consent was sought during the initial data collection with the use of two forms, one which was required by the King County public health system and the second which was required by the Institutional Review Board of the Pacific Institute for Research and Education (PIRE). Recognizing the ethical challenges inherent in work with refugees, the evaluation coordinator and trained interpreters made a significant effort to communicate the voluntary nature of participation both at the initial consent form signing and again at the scheduling of the second phase inventories (S. Verbillis-Kolp, personal communication, June 17, 2013). Illiteracy is a factor for some refugees therefore individuals who could not read in their first language were assisted by a trained interpreter in completing the study inventories.

\section{Measures}

The criterion variable, or dependent variable is the level of reported emotional distress, expressed as anxiety and depression. The predictor variables or independent variables include country of origin, age, gender, living location prearrival, number of prearrival traumas, number of postmigratory problems, reported levels of resource gains and losses, and self-efficacy. The table below outlines each variable according to the instrument that measures it.

\section{Table 1}

Variables by Instrument

Predictor variables

Basic Health Information Form Country of origin

Gender

Age

Living location prearrival 
Comprehensive Trauma

Inventory-Short Form 12

Generalized Self-efficacy Scale

Conservation of Resources

Postmigration Living Problems Inventory
Number of prearrival traumas

Self-efficacy

Resource gains

Resource losses

Number of postarrival problems

Outcome variable

Hopkins Symptom Checklist-25 Anxiety

Depression

\section{Predictor Variables.}

Demographic characteristics. The Basic Health Information form was used to collect demographic data necessary for the study and includes: country of origin, age, gender, and prearrival living location. The following demographic characteristics are recorded by fill in the blank: Age: Date of Birth and Age; Country of Origin: Burma, Iraq, Nepal; Gender: Male or Female; Living location prior to resettlement: Camp, Home country or Other.

Prearrival traumas. The Comprehensive Trauma Inventory-short form 12 was used to gather data on number and types of preflight traumas. The Comprehensive Trauma Inventory, consisting of 12 items was used to measure the number of significant prearrival traumas. Respondents choose from five columns designating the number of events for each item. The five choices range from: "No", 1-2 times, 3-12 times, 13-50 times and 51+ times. The inventory response range is $12-60$. 
The instrument was developed as a tool to evaluate war-related trauma in refugees and initially was a 164 -item list of potential events. The authors used a collaborative expert and participant process to identify a range of war-related experiences of refugees. Using qualitative focus groups in initial design, the tool was administered to $256 \mathrm{Kurds}$ and Vietnamese refugees along with an in-depth interview. These refugees reported an average of 150 events and the Comprehensive Trauma Inventory was modestly correlated with symptoms and impairment ultimately becoming the CTI-104 (Hollifield et al., 2005). The 104-item tool has been used to evaluate severity of traumatic exposure in refugees (Mutabaruka, Sejourne, Bui, Birmes \& Chabrol, 2012).

Additional testing of the tool occurred in a cross-sectional retrospective study of 36 Kurds and 31 Vietnamese for establishing validity (Hollifield et al., 2006). The CTI104 was measured against the New Mexico Refugee Symptom Checklist, the Shehan Disability Inventory-36 and the Postmigratory Social Support Inventory in addition to focus groups, and an in-depth interview.

The 12-item instrument was developed by the research team specifically for this study. Based on the above noted research the team chose the 12 items that most strongly correlated to pathology. This 12 -item instrument has not been validated (M. Hollifield, personal communication, March 7, 2014).

Postarrival living problems. The Post Migration Living Problems inventory was used to measure refugee specific postarrival challenges. The Post Migration Living Problems Inventory asked refugees to rate (on a five point scale ranging from no problem at all to a very serious problem) 23 typical problems faced by them in the months after resettlement. This instrument was developed by Silove, Steel, and McGary (1998) to 
assess current life stressors for asylums seekers. Its construct, development and design are not fully described by the authors however the instrument has been used by researchers to measure the number of problems in relation to symptoms of PTSD (Aragona, Pucci, Mazzetti \& Geraci, 2012). In two reported studies postmigratory problems were highly correlated with and made unique contributions to explaining depression, anxiety and somatization (Schweitzer et al., 2006; Schweitzer et al., 2011).

Resource gain and loss. The Conservation of Resources (COR) scale developed by Hobfoll in 1989 was used to gather data on perceptions of resource gain and loss. This instrument measures 72 resource gain and loss items from five domains, personal, interpersonal, material, work and health. Each item is scored on a Likert scale using a line image with the left end beginning at 0 and the right end at 4 . Respondents can read the words a little above the left end of the line spectrum at the 1, and a great deal above the 4. The respondents repeat the same items, scoring each of them as Losses and Gains. The response range of each inventory is 0-124. Hobfoll, Lilly and Jackson (1992) reported a moderate test re-test reliability with a range of .55 to .64 for this instrument. The 31 -item version was developed for specifically for this research by the Pathways research team and in consultation with the author (M. Hollifield, personal communication, March 7, 2014).

Self-efficacy. Self-efficacy was measured using the General Self-efficacy Scale developed by Ralf Schwarzer and Matthias Jerusalem in 1979. Ten items are rated on a 4-point Likert scale (1-Not true at all, 2-Hardly true, 3-Moderately true and 4-Exactly true). The ratings are summed for a total score (ranging from 10 to 40) with higher scores indicative greater self-efficacy. This scale has been adapted to 26 other languages. 
Examination of psychometric data from 23 different national groups on this unidimensional scale indicates that it has very good reliability, with Cronbach alphas ranging from .76 to .90 , with most in the range above .85 .

\section{Outcome/Criterion variable.}

Emotional distress (anxiety and depression). Emotional distress was measured with the Hopkins Symptom Checklist-25 (HSCL-25). The HSCL-25 measures anxiety and depression based on a set of commonly identified symptoms on a 4-point Likert scale (1-Not at all, 2-A little, 3-Quite a bit, and 4-Extremely). The scores can range from 25100. Within each subscale, the sum of all the items is divided by the number of items, to determine whether the results are clinically significant. Clinical significance is determined with a score of equal to or greater than 1.75 .

The HSCL-25 instrument was developed by expert consensus methods for use in the clinical setting and is a valid indicator of anxiety and depression for the general US population. The tool is considered transculturally valid. Initially, the Hopkins Symptom Checklist-90 was developed as an instrument to measure anxiety and depression (Derogatis, Lipman, Rickels, Uhlenhuth \& Covi, 1974; Derogatis \& Cleary, 1977). Subsequent research refined the instrument down to a 25 -item checklist that was later validated for use with Vietnamese and Kurdish populations (Kinzie et al.,1982). In research with 65 refugees from Vietnam, Laos, and Cambodia, the HSCL-25 demonstrated sensitivity and specificity against the Diagnostic and Statistical Manual of Mental Disorders (Mollica, Wyshak, de Marneffe, \& Khuon, 1987). Testing the psychometric properties of the HSCL-25 in the Arabic, English, Farsi, Russian, and 
Serbo-Croatian versions found that all Cronbach Alphas were above .80 suggesting internal validity in all five languages (Kleijn, Hovens, \& Rodenburg, 2001).

In an examination of psychometric properties of the HSCL-25, the Arabic, Farsi, Serbo-Croatian, and Russian versions were validated as reasonably good (Kleijn et al., 2001). In a meta-analysis in 2001 that reviewed 183 studies of instruments suggested to assess common symptoms of anxiety and depression, of the nine instruments adapted for use with refugees, only the HSCL-25 and the Beck Depression Scale were deemed both reliable and valid (Hollifield et al., 2002). Additional research testing cross-cultural reliability and validity using Ki-Swahili terms concluded that the instrument has criterion validity (Bolton, 2001). This assessment performed with refugees concluded that the instrument construct and internal reliability were good with a Cronbach alpha of .87, but the test-retest reliability was less adequate at .67. The HSCL-25's total score has consistently been shown to be highly correlated with severe traumatic stress of unspecified diagnosis, and the depression subscale score correlated with major depression Southeast Asian refugees (Hollifield et al., 2013).

Emotional distress, defined as anxiety and depression by the HSCL-25 is measured in clinical settings using the cut-off score of 1.75 , with scores above the cut-off considered clinically significant. The use of the HSCL-25 as an indicator of clinical significance is a practice standard used in therapeutic settings as a valid identification of individuals with symptoms that necessitate attention. It is worth noting that the use of this cut-off point for the predictor dichotomous variable differentiates between persons whose scores vary by .01. However, as some level of measure must be used to identify therapeutic need, using the 1.75 cut-off is consistent with the use in a therapy setting. 
This study uses the dichotomous results of the HSCL-25 of clinical significance or no clinical significance to align the research results with clinical use of the instrument.

\section{Instrument preparation}

All study instruments were translated using a community participatory research model. For each language group a community review committee was convened to discuss and establish consensus for the forward and backward translated instrument. The research team explained the intended communication of each question on every instrument. Using this method, the instruments were not only translated but each has been reviewed and linguistically adapted to ensure the use of language that best communicates the physical symptomology. The consent forms were included in this process (Hollifield et al., 2013).

All instruments in this study are considered reliable and valid measures for use with refugee populations and regarded as cultural adapted instruments for assessing symptoms of refugee trauma at this time (Derogatis \& Cleary, 1977; Mirzamani, Mohamadi, Mahmoudi \& Mirzamani, 2007; Oruc et al., 2008; Paunovic \& Ost, 2005; Silove et al., 2007). See Appendix Section for the instruments in their English version.

\section{Data collection and management}

The data were managed by the grant evaluation coordinator who administered the screenings, entered and checked all the data. The original instruments and all the electronic files were kept in locked cabinets throughout the process (S. Verbillis-Kolp, personal communication, June 17, 2013).

There were no incentives given to participants. Participants did however receive a thank you note and a package of tea following their participation in the second set of inventories (S. Verbilliskolp, personal communication, June 17, 2013). 


\section{Analysis}

Initial analysis was conducted to describe the sample. Binary logistic regression was applied to answer the research questions. Logistic regression predicts the impact of a series of independent variables on a dichotomous dependent variable and provides a discrete outcome of group membership (Tabaschnick \& Fidell, 2007). The independent variables may be continuous, dichotomous, or both and are useful when relationships may not be linear (Tabashnick \& Fidell, 2007). Assumptions of logistic regression include an absence of perfect multicollinearity, and a lack of specification errors (Meyers, Gamst \& Guarino, 2006). The best evaluation of goodness of fit is the overall model evaluation that measures whether the logistic model demonstrates an improvement over the intercept only model (Peng, Lee \& Ingersoll, 2002). Goodness of fit is also established with the Hosmer-Lemeshow test and the evaluation of the $R 2$ with the Nagelkerke (Tabashnick \& Fidell, 2007).

The outcome analysis of a logistic regression includes the Wald chi-squared statistic to determine whether the regression is a more effective predictor than the null model (Tabashnik \& Fidell, 2007). A benefit of the results from the logistic regression is that the odds ratio for each variable improves interpretation of the implications and interpretation of results of the research (Kerlinger \& Lee, 2000).

Two preliminary sets of simultaneous, or direct, logistic regression were performed. The first set analyzed the Prearrival Characteristics and then the Postarrival Perceptions, each separately, with the outcome variable of Anxiety. The second set analyzed the Prearrival Characteristics and then the Postarrival Perceptions, each separately, with the outcome variable of Depression. 
The two sets of variables identified as Prearrival Characteristics and Postarrival Perceptions were analyzed separately to maintain the distinction of preexisting qualities that a refugee possesses as they enter into resettlement, and the aspects that occur in the months just following arrival. In each set the variables are entered simultaneously by these distinct categories. Then, after determining the variables that were significant in each set, a logistic regression was repeated using the significant predictors to determine the overall predictors of anxiety and depression. 


\section{CHAPTER 4}

\section{RESULTS}

This study evaluated the predictability of emotional distress in refugees from factors identified as prearrival characteristics and postarrival perceptions. The results reported here are from five inventories completed by 170 refugees from Burma, Iraq, and Nepal.

\section{The data}

The study utilizes data collected in Seattle, Washington in 2010 over a seven month period. All data was collected under the supervision of the grant evaluation coordinator. Some participants completed the translated research instruments on their own while others used the assistance of specially trained interpreters. Initially, the instruments were administered in small groups but the evaluation coordinator concluded that this process was not effective and changed the process to home visits with individuals and families (S. Verbillis-Kolp, personal communication, June 17, 2013).

\section{Cleaning and preparation of data}

The grant coordinator performed a check of accuracy of the data entry. The data were reviewed in randomly chosen cases and instruments. Very few mistakes were identified and corrected (M. Hollifield, personal communication, June 17, 2013). Of the 170 cases used in this research the missing data varies from $0 \%$ for the HSCL- 25 to $5.3 \%$ 
for the Post Migratory Living Problems. The table below outlines the percentage of missing items in each instrument.

Table 2

Percentage of Missing Items by Instrument

\begin{tabular}{ll}
\hline Instrument & Percentage \\
\hline Hopkins Symptom Checklist-25 & $0.0 \%$ \\
Generalized Self Efficacy & $.06 \%$ \\
Conservation of Resources-Loss & $1.8 \%$ \\
Comprehensive Trauma Inventory & $2.4 \%$ \\
Conservation of Resources-Gains & $2.9 \%$ \\
Post Migratory Living Problems & $5.3 \%$ \\
\hline
\end{tabular}

\section{Collineararity}

With more than one predictor collinearity and multicollinearity must be evaluated. If any two variables are too closely correlated the coefficients will be imprecise causing large standard errors (Meyers, Gamst, \& Guarino, 2006). The results of a Pearson's $r$ determined a significant correlation between total scores on depression and anxiety of .863 . This suggests that results of the HSCL-25 for anxiety and depression be analyzed separately.

\section{Power}

Power was accessed using a standard formula based on sample size and number of predictors. In general reference to sample size and use of regression analysis, Tabachnick and Fidell (2007) suggest that $N$ should be bigger than $50+8(\mathrm{k})$, where $\mathrm{k}=$ the number of predictors. Therefore, the greater number of predictors the more you need 
to increase on your sample size. Another evaluation method is to sample at least 10-15 participants per predictor to ensure enough power and replicability. Establishing power is also important for replication of findings. Using the equation $N$ is larger than $50+8(\mathrm{k})$, the following applies: $170 \geq 50+8(9)$ or $170 \geq 131$ Using the second method with nine predictors the sample should be at least 90 or more conservatively 135.

However, some literature suggests a more conservative model for calculating sample size. One equation is $N=10 \mathrm{k} / \mathrm{p}$, when $\mathrm{k}$ is the number of variables and $\mathrm{p}$ is the smallest of proportions of negative or positive cases (Peduzzi, Concato, Kemper, Holford, \& Feinstein, 1996). For this study this calculation would suggest the following: $N=10 \times 6 / .20$ for anxiety and prearrival characteristics and $N=10 \times 6 / .24$ for depression and prearrival characteristics. The sample size suggested by this equation for the analysis of anxiety is 300 and for depression is 250 . The same calculation applied to the post arrival perceptions leads to the suggested sample size for anxiety at 150 and for depression at 125 .

\section{Model of analysis}

The method used in this study - two initial sets of logistic regression and then a third set of the significant variables — were determined after considering several issues. While the data could have been analyzed by entering all predictor variables into the equation at one time (Meyers, Gamst \& Guarino, 2006) a more conservative estimate of sample size to the number of predictors supports the separation of the analysis (Peduzzi, Concato, Kemper, Holford, \& Feinstein, 1996).

Creating two sets of predictor variables strengthens the model's ability to differentiate the predictors based on the theoretical design (Tabashnick \& Fidell, 2007). 
The separated analysis model controls for temporality and reflects the experience of the refugee. At the moment of arrival, the refugee possesses the prearrival characteristics and is then impacted by the postarrival realities. The separated analysis aligns with the theoretical model. The subsequent analysis of the significant predictors then serves to build a stronger model with fewer predictors (Tabashnik \& Fidell, 2006; Worster, Fan, \& Ismaila, 2007).

\section{Description of the sample}

A total of 170 refugees took part in the study including 43 from Burma, 68 from Iraq, and 59 from Nepal. Of the sample, the Burmese group represents $25.3 \%$, the Iraqi group represents $40 \%$, and the Nepali group represents $34.7 \%$.

\section{Demographic characteristics overview}

The following demographics of the sample: country of origin, ethnic group, gender, age, and living location prior to resettlement are displayed in the table below.

Table 3

Frequencies of Prearrival Characteristics $(N=170)$

\begin{tabular}{lcc}
\hline Characteristics & $N$ & $\%$ \\
\hline $\begin{array}{l}\text { Country of origin } \\
\text { Burma }\end{array}$ & 43 & 25.3 \\
Iraq & 68 & 40 \\
Nepal & 59 & 34.7 \\
Gender & & \\
Female & 84 & 49.4 \\
Male & 86 & 50.6 \\
\hline
\end{tabular}


$\underline{\text { Age by Decade }}$

$14-19$

20-29

30-39

40-49

50 and over

$\underline{\text { Living location }}$

Camp

Home country

Other
27

51

42

37

13

13

24.7

21.8

7.6

30.0

48.2

13.5

38.2

\section{Demographics by country of origin}

Country of origin and ethnic groups. The sample includes refugees from three originating country locations. Refugees from Nepal in this data set all identify as Bhutanese and speak Nepali. Refugees from Iraq in this data set all identify as Iraqi and speak Arabic. However, the refugees from Burma in this data set identify themselves as Burman, Chin, Karen, and Karenni, each speaking the ethnic or tribal language of the same name. The data set includes the ethnicities of the cases from Burma to distinguish first language. Although ethnically diverse, the sample from Burma will be considered one group. The table below outlines each ethnic group by country of origin.

Table 4

Ethnicity by Country of Origin

\begin{tabular}{llll}
\hline Country & Ethnicity & $n$ & Percentage \\
\hline Burma & & & \\
\hline
\end{tabular}




$\begin{array}{lcc}\text { Burmese } & 5 & 2.9 \% \\ \text { Chin } & 20 & 11.8 \% \\ \text { Karen } & 15 & 8.8 \% \\ \text { Karenni } & 3 & 1.8 \% \\ \text { Total } & 43 & 25.3 \%\end{array}$

$\underline{\text { Iraq }}$

Nepal

Iraqi $\quad 68 \quad 40 \%$

Bhutanese $\quad 59 \quad 34.7 \%$

Gender. Gender was fairly equally represented with the sample including 84 females and 86 males. The table below outlines the frequencies of each gender by country of origin.

Table: 5

Frequencies of Gender by Country of Origin

\begin{tabular}{lcccccc}
\hline$N=170$ & Total & $\%$ & Male & $\%$ & Female & $\%$ \\
& & & 86 & $50.6 \%$ & 84 & $49.4 \%$ \\
\hline Burma & 43 & $25.3 \%$ & 27 & $15.9 \%$ & 16 & $9.4 \%$ \\
Iraq & 68 & $40.0 \%$ & 32 & $18.8 \%$ & 36 & $21.2 \%$ \\
Nepal & 59 & $34.7 \%$ & 27 & $15.9 \%$ & 32 & $18.8 \%$ \\
\hline
\end{tabular}

Age. The age of participants spanned six decades with very small numbers over 60 years of age, with the mean age of 32.2 and a standard deviation of 11.9. The median ages differ significantly with the Nepali median age nine years younger than the Burmese. The table below outlines the frequencies of age by country of origin. 
Table 6

Age by country of origin

\begin{tabular}{llll}
\hline Country of Origin & Mean age & $\begin{array}{l}\text { Standard } \\
\text { Deviation }\end{array}$ & Median age \\
\hline Burma & 32.51 & 13.6 & 35.0 \\
Iraq & 33.6 & 10.2 & 34.5 \\
Nepal & 29.5 & 12.1 & 26.0 \\
Total & 32.20 & 11.9 & 30.5 \\
\hline
\end{tabular}

Prearrival living location. Previous living situation is defined as the location in which the refugee resided just before resettlement and includes camp, home country and other. The chart below identifies the living location by Country of Origin. The Burmese all lived in camps except for the Chin who fled to other countries, living on the run.

Many Iraqis also responded to the category Other if they lived in another county while waiting as there were no camps for this population. The table below outlines the frequencies of prearrival living location by Country of Origin.

Table 7

Living Location Prior to Resettlement by Country of Origin

\begin{tabular}{llllllll}
\hline Location & $n$ & camp & $\begin{array}{l}\% \text { of } \\
\text { total }\end{array}$ & $\begin{array}{l}\text { home } \\
\text { country }\end{array}$ & $\begin{array}{l}\% \text { of } \\
\text { total }\end{array}$ & Other & $\begin{array}{l}\% \text { of } \\
\text { total }\end{array}$ \\
\hline Burma & 43 & 23 & $13.5 \%$ & 0 & $0 \%$ & 20 & $11.7 \%$ \\
Iraq & 68 & 4 & $2.4 \%$ & 19 & $11.2 \%$ & 45 & $26.5 \%$ \\
Nepal & 59 & 55 & $32.3 \%$ & 4 & $2.4 \%$ & 0 & $0 \%$ \\
\hline
\end{tabular}

\section{Predictor/Outcome variable results}


Results for all inventory and scales in the dataset are displayed in table below.

Table 8

Description of Predictor and Outcome Variables

Predictor Variable results

\begin{tabular}{|c|c|c|c|c|}
\hline$N$ & Mean & $\begin{array}{l}\text { Standard } \\
\text { Deviation }\end{array}$ & $\begin{array}{l}\text { Scale } \\
\text { range }\end{array}$ & $\begin{array}{l}\text { Respondent } \\
\text { range }\end{array}$ \\
\hline
\end{tabular}

Prearrival

$\begin{array}{lrrrrr}\text { CTI } & 166 & 19.03 & 6.43 & 12-60 & 12-44 \\ \text { GSE } & 169 & 28.5 & 7.20 & 0-40 & 8-40\end{array}$

Post Arrival

$\begin{array}{lccccc}\text { COR-Losses } & 167 & 36.6 & 24.75 & 0-124 & 0-96 \\ \text { COR-Gains } & 165 & 46.28 & 23.68 & 0-124 & 2-111 \\ \text { PMLP } & 161 & 32.22 & 16.77 & 0-92 & 0-74\end{array}$

Outcome variable results

HSCL-25

$\begin{array}{lrrrrr}\text { Anxiety } & 170 & 1.45 & .497 & 1-4 & 1-3.30 \\ \text { Depression } & 170 & 1.54 & .571 & 1-4 & 1-3.67\end{array}$

\section{Predictor variable results by Country of Origin}

The results of each inventory or scale by country of origin are outlined below.

Number of prearrival traumas. The mean score of the Nepali group is much

lower than both the Iraqi and Burmese group. The table below outlines the mean and standard deviation of prearrival traumas by country of origin.

Table 9

Prearrival Traumas by Country of Origin 


\begin{tabular}{llllll}
\hline & $N$ & Mean & $\begin{array}{l}\text { Standard } \\
\text { deviation }\end{array}$ & Range & Median \\
\hline Burma & 35 & 20.49 & 5.04 & $12-33$ & 20.0 \\
Iraq & 68 & 21.01 & 7.83 & $11-44$ & 19.0 \\
Nepal & 58 & 15.61 & 3.46 & $12-32$ & 15.0 \\
Total & 166 & 19.03 & 6.43 & $0-44$ & 17.0 \\
\hline
\end{tabular}

Self-efficacy. The mean scores by country of origin demonstrate the gap between Burmese reported self-efficacy and Iraqi reported self-efficacy. The range of the scores for self-efficacy sorted by country of origin indicate a significant difference at the lower end when comparing Burmese to Nepali's. The table below outlines the mean and standard deviation of self-efficacy by country of origin.

Table 10

Self-efficacy by Country of Origin

\begin{tabular}{lccll}
\hline & $N$ & Mean & $\begin{array}{l}\text { Standard } \\
\text { Deviation }\end{array}$ & Range \\
\hline Burma & 43 & 24.39 & 6.17 & $8-38$ \\
Iraq & 67 & 28.47 & 7.17 & $11-40$ \\
Nepal & 59 & 31.54 & 6.17 & $17-40$ \\
Total & 169 & 28.50 & 7.20 & $8-40$ \\
\hline
\end{tabular}

COR-gains and losses. Across the three countries, gains were relatively consistent while the perceived losses vary widely with the Burmese mean at 17.45 and the Nepali at more than twice that at 45.68. Mean resource gains reported by Burmese were 42.74 more than twice the mean of losses. The highest mean scores were from the 
Nepalis at 45.68 for losses and 53.46 for gains. The table below outlines the means and standard deviation of resource gains and losses by country of origin.

Table 11

Resource Gains and Losses by Country of Origin

\begin{tabular}{lllllll}
\hline & $N$ & Gains & $\begin{array}{l}\text { Standard } \\
\text { Deviation }\end{array}$ & $N$ & Losses & $\begin{array}{l}\text { Standard } \\
\text { Deviation }\end{array}$ \\
\hline Burma & 39 & 42.74 & 23.48 & 40 & 17.45 & 16.78 \\
Iraq & 67 & 42.01 & 26.26 & 68 & 40.0 & 26.27 \\
Nepal & 59 & 53.46 & 18.92 & 59 & 45.68 & 20.42 \\
Total & 165 & 46.28 & 23.68 & 167 & 36.60 & 24.75 \\
\hline
\end{tabular}

Number of postarrival problems. The number of reported postresettlement problems varies between country of origin with the Burmese at the lowest and the Iraqi's at the highest. The table below outlines the means and standard deviation of postarrival problems by country of origin.

Table 12

Postarrival Problems by Country of Origin

\begin{tabular}{lllll}
\hline & $N$ & Mean & $\begin{array}{l}\text { Standard } \\
\text { deviation }\end{array}$ & Range \\
\hline Burma & 35 & 25.46 & 14.85 & $0-59$ \\
Iraq & 68 & 36.51 & 19.14 & $0-74$ \\
Nepal & 58 & 31.28 & 13.28 & $2-66$ \\
Total & 161 & 32.22 & 16.77 & $0-74$ \\
\hline
\end{tabular}


Emotional Distress. The table below outlines the means and standard deviation of emotional distress, anxiety and distress by country of origin.

Table 13

Anxiety and Depression by Country of Origin

\begin{tabular}{lccccc}
\hline & \multicolumn{3}{c}{ Anxiety } & \multicolumn{2}{c}{ Depression } \\
& $N$ & Mean & $\begin{array}{l}\text { Standard } \\
\text { Deviation }\end{array}$ & Mean & $\begin{array}{l}\text { Standard } \\
\text { Deviation }\end{array}$ \\
\hline Burma & 43 & 1.28 & .268 & 1.32 & .308 \\
Iraq & 68 & 1.67 & .608 & 1.83 & .682 \\
Nepal & 59 & 1.31 & .383 & 1.36 & .421 \\
Total & 170 & 1.45 & .497 & 1.54 & .571 \\
& & & & & \\
\hline
\end{tabular}

\section{Country of origin profiles}

Burma. The Burmese represent the smallest group in the sample with twice as many males as females. The age distribution is relatively equal. The entire Chin ethnic group fled to other countries where there were no refugee camps. The Burmese sample scored the lowest self-efficacy, postresettlement problems, and emotional distress scores. The prearrival traumas and COR gains scores were very close to the Iraqi's while the COR losses were one-half of the mean score for all three countries.

Iraq. The Iraqis represent the largest group in the sample consisting of equal distribution of males to female with a large older-aged population. Due to the particular circumstances of the Iraq situation, most of the Iraqi sample fled to neighboring countries while less than one-third remained in their home country until resettlement. The Iraqi sample had the highest mean score of emotional distress, number of prearrival traumas, and postarrival problems. The COR gains were very close to equal to the Burmese and 
the COR losses were mid-range between the Burmese and Nepali groups. The Iraqi sample had a self-efficacy mean between the Nepali and Burmese sample.

Nepal. The Nepali sample is smaller than the Iraqi group but one-third larger than the Burmese with a relatively equal gender distribution. This group is younger than the other two groups with a high concentration in the 20 to 29 year age range. The vast majority of the Nepalis lived in refugee camps before resettlement with the exception of four cases. The Nepali respondents had the highest mean score for self-efficacy and both COR gains and losses with the lowest mean score for number of prearrival traumas and emotional distress. The Nepali sample had a postarrival problem score between the Iraqi and Burmese sample.

\section{Analysis}

\section{Research question 1}

To what extent do prearrival characteristics, country of origin, gender, age, prearrival traumas, prearrival living location and self-efficacy, predict reported levels of emotional distress, (anxiety and depression), in recently arrived refugees?

Anxiety. A logistic regression was performed to investigate how well country of origin, gender, age, living location prior to migration, number of prearrival traumas, and generalized self-efficacy can predict anxiety in newly arrived refugee adults. Results of the logistic analysis indicate that the six predictor model provides a statistically significant improvement over the constant only model, $X 2(6, N=170)=51.87, \mathrm{p}<0.001$. The Nagelkerke pseudo $R 2$ indicates that the model accounted for $42 \%$ of the variance. This suggests that the set of indicators discriminates between those with clinically significant anxiety and those without significant anxiety. Prediction success for the cases 
used in the development of the model was relatively high with an overall predictive success rate of $85.5 \%$, and correct prediction rates of $95.4 \%$ for those not clinically significant and $47.1 \%$ for those with clinically significant anxiety. The Wald test reports that four of the predictors are statistically significant predictors of anxiety with the following results while controlling for the other variables:

- Females are three times less likely to be clinically anxious than males,

- Burmese are 32 times more likely to be clinically anxious than Nepali's,

- As self-efficacy increases a refugee is somewhat less likely to be clinically anxious, and

- As the number of prearrival traumas increase a refugee is significantly more likely to be clinically anxious.

Without considering any other information the likelihood of probability of a correct prediction is $79.4 \%$ with the overall accuracy increased to $85.5 \%$.

Depression. A logistic regression was performed to investigate how well country of origin, gender, age, living location prior to migration, number of prearrival traumas, and generalized self-efficacy, predict depression in newly arrived refugee adults. Results of the logistic analysis indicate that the six predictor model provides a statistically significant improvement over the constant only model, $X 2(6, N=170)=52.24, \mathrm{p}<0.001$. The Nagelkerke pseudo $R 2$ indicates that the model accounted for $40 \%$ of the variance. This suggests that the set of indicators discriminates between those with clinically significant depression and those without clinically significant depression. Prediction success for the cases used in the development of the model was relatively high with an overall predictive success rate of $81.8 \%$, and correct prediction rates of $94.4 \%$ for those 
not clinically significant and $43.9 \%$ for those clinically significant. The Wald test reports that three of the predictors are statistically significant predictors of depression with the following results while controlling for the other variables:

- Burmese are 14 times more likely to be depressed than Nepali's,

- As self-efficacy increases a refugee is somewhat less likely to be clinically depressed, and

- As number of prearrival traumas increase a refugee is significantly more likely to be clinically depressed.

Without considering any other information the likelihood of probability of a correct prediction is $75.2 \%$ and the overall accuracy increased to $81.8 \%$. The table below outlines the results of the logistic regression of the prearrival characteristics.

Table 14

Logistic Regression Results Prearrival Characteristics

\begin{tabular}{|c|c|c|c|c|c|c|c|}
\hline & & $\bar{\beta}$ & Wald & Significance & $\begin{array}{l}\text { Exp } \\
\text { (B) }\end{array}$ & $\begin{array}{l}95 \% \\
\text { Lower }\end{array}$ & $\begin{array}{l}95 \% \\
\text { Upper }\end{array}$ \\
\hline \multirow[t]{8}{*}{$A N X$} & Burmese & 3.469 & 8.93 & .003 & 32.093 & 3.299 & 312.217 \\
\hline & Iraq & .179 & .038 & .846 & 1.196 & .195 & 7.326 \\
\hline & Female & -1.086 & 4.349 & .037 & .337 & .122 & .937 \\
\hline & Camp & .387 & .179 & .672 & 1.473 & .245 & 8.842 \\
\hline & Other living & -.155 & .057 & .812 & .856 & .238 & 3.078 \\
\hline & Age & .032 & 2.097 & .148 & 1.033 & .989 & 1.079 \\
\hline & Self-efficacy & -.139 & 14.211 & .000 & .870 & .810 & .936 \\
\hline & Prearrival traumas & .124 & 8.669 & .003 & 1.132 & 1.042 & 1.230 \\
\hline
\end{tabular}




\begin{tabular}{llllllll}
\hline & & & Wald & Significance & $\begin{array}{l}\text { Exp } \\
(\beta)\end{array}$ & $\begin{array}{l}95 \% \\
\text { lower }\end{array}$ & $\begin{array}{l}95 \% \\
\text { upper }\end{array}$ \\
\hline$D E P$ & Burmese & 2.691 & 7.457 & $\mathbf{. 0 0 6}$ & 14.747 & 2.137 & 101.745 \\
& Iraq & -.085 & .010 & .920 & .918 & .173 & 4.867 \\
Female & -.382 & .669 & .413 & .682 & .273 & 1.705 \\
Camp & -.041 & .002 & .962 & .960 & .176 & 5.225 \\
Other living & -.820 & 1.717 & .190 & .440 & .129 & 1.502 \\
Age & .018 & .754 & .385 & 1.018 & .978 & 1.059 \\
Self-efficacy & -.105 & 9.890 & $\mathbf{. 0 0 2}$ & .900 & .843 & .961 \\
Prearrival traumas & .148 & 11.339 & $\mathbf{. 0 0 1}$ & 1.160 & 1.064 & 1.265 \\
\hline
\end{tabular}

\section{Research question 2}

To what extent do postarrival perceptions, conservation of resources, gained and lost, number of postarrival problems, predict reported levels of emotional distress, anxiety and depression, in recently arrived refugees?

Anxiety. A logistic regression was performed to investigate how well conservation of gains and losses, and number of postarrival problems can predict anxiety in newly arrived refugee adults. Results of the logistic analysis indicate that the three predictor model provides a statistically significant improvement over the constant only model, $X 2(3, N=170)=43.52, \mathrm{p}<0.001$. The Nagelkerke pseudo $R 2$ indicates that the model accounted for $37 \%$ of the variance. This suggests that the set of indicators discriminates between those with clinically significant anxiety and those without significant anxiety. Prediction success for the cases used in the development of the model was relatively high with an overall predictive success rate of $82 \%$, and correct prediction 
rates of $94 \%$ for those not clinically significant and 38\% for those clinically significant. The Wald test reports that three of the predictors are statistically significant predictors of anxiety with the following results while controlling for the other variables:

- As the perception of resource loss increases a refugee is significantly more likely to be anxious,

- As perception of resource gain increases a refugee is significantly less likely to be anxious, and

- As the number of postarrival problems increase a refugee is significantly more likely to be anxious.

Without considering any other information the likelihood of probability of a correct prediction is $78.2 \%$ and the overall accuracy increased to $82.1 \%$.

Depression. A logistic regression was performed to investigate how well conservation of gains and losses, and number of postarrival problems can predict depression in newly arrived refugee adults. Results of the logistic analysis indicate that the three predictor model provides a statistically significant improvement over the constant only model, $X 2(3, N=170)=72.93, \mathrm{p}<0.001$. The Nagelkerke pseudo $R 2$ indicates that the model accounted for $54 \%$ of the variance. This suggests that the set of indicators discriminates between those with clinically significant depression and those without significant depression. Prediction success for the cases used in the development of the model was relatively high with an overall predictive success rate of $83.3 \%$, and correct prediction rates of $93.0 \%$ for those not clinically significant and $56.1 \%$ for those with clinically significant depression. The Wald test reports that two of the predictors are 
statistically significant predictors of depression with the following results while controlling for the other variables:

- As the perception of resource loss increases a refugee is significantly more likely to be clinically depressed, and

- As the number of postarrival problems increase a refugee is significantly more likely to be clinically depressed.

Without considering any other information the likelihood of probability of a correct prediction is $73.7 \%$ and the overall accuracy increased to $83.3 \%$. The table below outlines the results of the logistic regression of the postarrival perceptions.

Table: 15

Logistic Regression Results Postarrival Perceptions

\begin{tabular}{llllllll}
\hline & $\beta$ & Wald & $\begin{array}{l}\text { Signifi- } \\
\text { Cance }\end{array}$ & Exp $(\beta)$ & $\begin{array}{l}95 \% \\
\text { lower }\end{array}$ & $\begin{array}{l}95 \% \\
\text { upper }\end{array}$ \\
\hline$A N X$ & Resource loss & .027 & 6.486 & $\mathbf{. 0 1 1}$ & 1.027 & 1.006 & 1.049 \\
& Resource gain & -.023 & 4.018 & $\mathbf{. 0 4 5}$ & .977 & .955 & .999 \\
& $\begin{array}{l}\text { Postarrival } \\
\text { problems }\end{array}$ & .057 & 11.308 & $\mathbf{. 0 0 1}$ & 1.059 & 1.024 & 1.095 \\
DEP & $\begin{array}{l}\text { Resource loss } \\
\text { Resource gain }\end{array}$ & .059 & 20.518 & $\mathbf{. 0 0 0}$ & 1.061 & 1.034 & 1.089 \\
& $\begin{array}{l}\text { Postarrival } \\
\text { problem }\end{array}$ & .062 & 11.393 & $\mathbf{. 0 0 1}$ & 1.064 & 1.026 & 1.104
\end{tabular}

\section{Analysis of overall factors}

For the purposes of confirming a final set of predictor variables and in an effort to identify a focal area for program and policy discussion, a logistic regression was repeated using the predictor variables that were significant in the two sets. Below are the results. 
Anxiety. A logistic regression was performed to investigate how well gender, country of origin, generalized self-efficacy, number of prearrival traumas, conservation of resources-losses, and number of postarrival problems can predict anxiety in newly arrived refugee adults. Results of the logistic analysis indicate that the six predictor model provides a statistically significant improvement over the constant only model, $X 2$ $(6, N=170)=64.30, \mathrm{p}<0.001$. The Nagelkerke pseudo $R 2$ indicates that the model accounted for $52 \%$ of the variance. This suggests that the set of indicators discriminates between those with clinically significant anxiety and those without significant anxiety. Prediction success for the cases used in the development of the model was relatively high with an overall predictive success rate of $84.8 \%$, and correct prediction rates of $94.0 \%$ for those not clinically significant and $52.9 \%$ for those with clinically significant anxiety. The Wald test reports that four of the predictors are statistically significant predictors of anxiety with the following results while controlling for the other variables:

- Females are three times less likely to be clinically anxious than men,

- As self-efficacy increases refugees are somewhat less likely to be clinically anxious,

- As perceived resource losses increase refugees are significantly more likely to be clinically anxious, and

- As perceived number of postarrival problems increase refugees are significantly more likely to be clinically anxious.

Without considering any other information the likelihood of probability of a correct prediction is $77.5 \%$ and the overall accuracy increased to $84.8 \%$. 
Depression. A logistic regression was performed to investigate how well country of origin, generalized self-efficacy, number of prearrival traumas, conservation of resources-losses, and number of postarrival problems can predict depression in newly arrived refugee adults. Results of the logistic analysis indicate that the five predictor model provides a statistically significant improvement over the constant only model, $X 2$ $(5, N=170)=101.57, \mathrm{p}<0.001$. The Nagelkerke pseudo $R 2$ indicates that the model accounted for $70 \%$ of the variance. This suggests that the set of indicators discriminates between those with clinically significant depression and those without significant depression. Prediction success for the cases used in the development of the model was relatively high with an overall predictive success rate of $91.5 \%$, and correct prediction rates of $96.4 \%$ for those not clinically significant and $78.0 \%$ for those with clinically significant depression. The Wald test reports that three of the predictors are statistically significant predictors of depression with the following results while controlling for the other variables:

- As self-efficacy increases refugees are somewhat less likely to be clinically depressed,

- As the number of prearrival traumas increases refugees are significantly more likely to be clinically depressed, and

- As the number of resources losses increase refugees are significantly more likely to be clinically depressed.

Without considering any other information the likelihood of probability of a correct prediction is $73.2 \%$ and the overall accuracy increased to $88.9 \%$. The table below outlines the results of the logistic regression of the overall factors of significance. 
Table: 16

Logistic Regression of Overall Factors

\begin{tabular}{|c|c|c|c|c|c|c|c|}
\hline & & $\beta$ & Wald & Significance & $\begin{array}{l}\operatorname{Exp} \\
(ß)\end{array}$ & $\begin{array}{l}95 \% \\
\text { lower }\end{array}$ & $\begin{array}{l}95 \% \\
\text { upper }\end{array}$ \\
\hline \multirow[t]{9}{*}{$A N X$} & Female & -1.132 & 4.079 & .043 & .322 & .107 & .967 \\
\hline & Burmese & .719 & .408 & .523 & 2.052 & .226 & 18.625 \\
\hline & Iraqi & -.656 & 1.008 & .315 & .519 & .144 & 1.868 \\
\hline & Self-efficacy & -.133 & 9.799 & .002 & .875 & .805 & .951 \\
\hline & Prearrival traumas & .068 & 2.096 & .148 & 1.070 & .976 & 1.173 \\
\hline & Resource loss & .033 & 5.822 & .016 & 1.034 & 1.006 & 1.062 \\
\hline & Resource gain & -.013 & .946 & .331 & .987 & .961 & 1.014 \\
\hline & $\begin{array}{l}\text { Postmigration } \\
\text { problems }\end{array}$ & .043 & 4.244 & .039 & 1.044 & 1.002 & 1.087 \\
\hline & & $\beta$ & Wald & Significance & $\begin{array}{l}\text { Exp. } \\
(ß)\end{array}$ & $\begin{array}{l}95 \% \\
\text { lower }\end{array}$ & $\begin{array}{l}95 \% \\
\text { upper }\end{array}$ \\
\hline \multirow[t]{5}{*}{$D E P$} & Burmese & -.641 & .510 & .475 & .527 & .091 & 3.059 \\
\hline & Self-efficacy & -.173 & 12.730 & .000 & .841 & .765 & .925 \\
\hline & Prearrival traumas & .177 & 9.067 & .003 & 1.194 & 1.064 & 1.339 \\
\hline & Resource loss & .099 & 23.257 & .000 & 1.104 & 1.061 & 1.150 \\
\hline & $\begin{array}{l}\text { Post migration } \\
\text { problems }\end{array}$ & .037 & 2.378 & .123 & 1.037 & .990 & 1.087 \\
\hline
\end{tabular}

\section{Synthesis of results}

Of the factors analyzed in this study, those that most strongly predicted both anxiety and depression were self-efficacy and the number of perceived resource losses. The factors that most strongly predicted anxiety alone were gender and number of 
postarrival problems and the factor that most strongly predicted depression alone was number of prearrival traumas. 


\section{CHAPTER 5}

\section{DISCUSSION}

The purpose of this exploratory study is to increase evidence-based knowledge regarding refugee functioning at the time of resettlement. The study serves to identify specific factors that impact emotional distress in refugees in the early months following migration. Recognizing the US policy emphasis on rapid employment for refugees, this study was designed to provide more insight into the challenges facing refugees at this critical period.

\section{Method}

The study explored the role of prearrival characteristics and postarrival perceptions in predicting emotional distress in 170 refugees from Burma, Iraq and Nepal during the first three months following arrival to Seattle, Washington. A series of binary logistic regressions were performed to identify specific factors that predicted anxiety and depression.

\section{Summary of findings}

The set of primary attributes that were predictive of emotional distress in newly arrived refugees included self-efficacy, gender, prearrival traumas, perceived resource loss, and postarrival problems. The specific predictors of anxiety and depression were as follows: 
- The greater a newly arrived refugee's reported self-efficacy the lower the probability of being clinically anxious or depressed.

- The greater a newly arrived refugee's perceived sense of resource loss the greater the probability of being clinically anxious or depressed.

- A newly arrived male refugee when compared to a female refugee is more likely to be clinically anxious.

- A newly arrived refugee reporting a higher number of postarrival problems is more likely to be clinically anxious.

- A newly arrived refugee reporting a higher number of prearrival traumas is more likely to be clinically depressed.

Overall, the logistic regression model tested better predictive success rate of those that met the criteria for clinical depression than those that met the criteria for clinical anxiety.

\section{Primary findings of the study}

This study expands our understanding in the areas of self-efficacy and resource loss in relation to refugee populations. This knowledge adds valuable support to the limited but growing empirical research with refugees.

Self-efficacy. It is generally accepted that self-efficacy contributes to a person's overall wellbeing and emotional health. Previous studies of refugees have concluded that positive self-efficacy is related to positive outcomes (Ferren, 1999; Loughry \& Flouri, 2001; Sulaiman-Hill \& Thompson, 2013). The results of this study suggest a link between self-efficacy and the predictability of reduced levels of emotional distress. Although not the strongest predictor in the study, this conclusion suggests that self- 
efficacy is a factor in a refugee exhibiting less emotional distress during the period of adaptation.

These results encourage us to explore how self-efficacy is understood and expressed in cultures that value collectivism and collective perspectives on decisionmaking. Self-efficacy is often considered a Western concept that is grounded in cultural frameworks that are individualistic. Therefore understanding how self-efficacy is expressed in refugee cultures could add to our capacity to support improved functioning within refugee population. Further research in this area is needed.

Resource loss. The concept of loss is a central theme of the refugee experience but no research has been recorded that assesses the link between resource loss and emotional distress in refugee populations. This study gives a new perspective on how the perception of loss may impact the period of adaptation. Our ability to more effectively understand how individual refugees perceive the gains and losses they have experienced could lead to improved methods of integration of refugees into US communities.

It is widely understood that refugees have suffered significant losses that are acknowledged in the refugee policy response. From the start of the UN intervention and throughout the refugee process, the program responses are designed to fill the resource gaps left from the refugee's experience (UNHCR, 2012). However, it is also true that during the middle period of transition many refugees are burdened with limited physical resources. Prior to resettlement refugee individuals and families often make difficult decisions about accessing basic items like food and clothing in an effort to survive. Refugees report having to choose to leave the safety of the camps, cross into dangerous territories in search of work, or make personal choices regarding survival that were 
personally degrading. It is reasonable then to believe that resettlement situations that mimic these former experiences may reactivate the stress response. Further research is needed to evaluate resource loss and emotional distress with other refugee groups.

Gender. Previous studies have reported mixed results regarding gender as an indicator, some reporting either that females are at greater risk or that gender has no influence on predicting emotional distress. In contrast, this study suggests that males are at a greater risk for experiencing anxiety. These results open up a new perspective on the pressure felt on the traditional head of households during this particular period of adaptation.

While the concerns for women in resettlement may be valid, based on issues of vulnerability, the findings of this study suggest that it is important to recognize the unique challenges faced by men. The expectations of the resettlement process in the US places a time-limited pressure on the refugee to secure employment. The results of the study suggest that at this stage when individuals are considering the challenge of transition into employment men may be feeling increased pressure and responsibility.

Prearrival traumas. This study supports a large number of previous research studies stating that a history of trauma is predictive of emotional distress in refugees (Hollifield et al., 2002; Momartin et al., 2004; Nickerson, Bryant, Silove \& Steele, 2011). It has been well established that experiences of trauma contribute to increased mental health issues (Hollifield et al., 2006; Keller et al., 2006; Mollica, 2006).

Most literature regarding refugee migration refers to the history of trauma as a primary influence on adaptation (Kleijn et al., 2001; Knipsheer \& Kleber, 2006; Mollica, 2006). In this study however, prearrival traumas are one of seven contributing factors 
identified as significant during the early months of resettlement. With the division of anxiety and depression as outcome variables for this study the significant finding is that prearrival traumas uniquely contributes to depression.

Postarrival problems. It is logical to conclude that refugees with problems during resettlement will have increased anxiety, however, there is little-to-no research of postmigratory problems with refugees. Postmigration challenges, especially those that reinforce the lack of choice or control can bring increased fear for some refugees especially when employment is uncertain (Vissacaro, 2009). The results of this study make an important empirical link between problems faced by refugees during resettlement and anxiety.

\section{Contribution of the study}

With a dearth of research related to the early period following migration, these findings make a unique contribution to the empirical knowledge regarding refugee migration adaptation. The results of this study provide a window into the needs of refugees at a critical time in the adaptation process. The discussion that follows will focus on interpreting these findings in a manner that may help resettlement programs to integrate this information into policy and practice.

\section{Implications for social work}

Before exploring the study implications for social work practice it is vital to review the underlying reasons for this study. The small body of knowledge regarding refugee health continues to limit us in responding in creative and useful ways (Weine, 1990). It is essential to the future of social work that, as a profession, we are able to expand skill development in cultural competency (Tseng, 2004). Social work skills and 
expanded understanding come with practice and exposure. This study enhances our capacity to respond by providing new perspectives for the engagement of refugee clients and refugee groups.

It is particularly important at this time in history that we as social workers develop a broader set of skills for assessing, understanding and treating the impact of the refugee experience. With the complexity of issues raised when working with refugees populations - the cultural influences added to the behavioral impact on the individual that occurs following migration and trauma—social work curriculums need to improve preparation of students beyond exposure to concepts of diversity. Educational and training materials that effectively develop cultural competency skills in social workers are needed. Additionally, increased capacity with critical thinking models is necessary for social workers to address these complex issues.

\section{Considerations for practice}

These results add support to the concept that arrival to the country of resettlement, in and of itself, does not provide the resolution of emotions that either refugees expect or some policy makers would like to purport (Drachman, 1992; Weine, 2011). Although individuals working in resettlement programs recognize that refugees with significant histories of trauma or loss may need additional support, there are no program-based mechanisms to assess refugee needs. Recent moves to provide mental health screening during the refugee health evaluation have returned mixed reviews by resettlement program staff. Local agencies must depend on community mental health providers that may or may not have the capacity to respond to the unique needs of the population. 
While there are no published studies that assess the problems that are faced after migration, anecdotally, resettlement workers would agree that refugees who have added health, family or employment challenges are more likely to struggle in this early phase of adaptation. And, most staff working with refugees would argue that there are some refugees who, despite having experienced the most traumatic of circumstances, continue to forge ahead and meet goals set for them. While these assumptions are already considered within resettlement programs the specific empirical evidence of this study can serve to promote a more intentional application of these findings into the design of interventions.

An important result of this study is the division of emotional distress into separate analysis of anxiety and depression resulting in the distinction of factors predicting each. These results indicate that challenging events in the past are more likely to lead to symptoms of depression and challenging events in the present are more likely to lead to anxiety. Future research may consider how these individual factors impact both mental health screening and assessment of refugees.

Loss. Refugee loss is significant and yet there are no formal mechanisms within the resettlement system that acknowledge them. The unstated presumption is that refugees are better off in the US, and therefore there is no need to recognize these losses or the grief that accompanies them. The lack of an opportunity to grieve promotes the denial of feelings like sadness and pain and, inadvertently, supports the notion that these normal emotions should not be expressed. Whether lack of awareness on the part of resettlement staff or misguided intentions, the pull yourself up by the bootstraps mentality often leads to a lack of recognition of the challenges that are being felt. 
Grief is pain and pain that is left unacknowledged can lead to expressions of distress. The significant losses associated with migration when recognized allow the refugee to move past the initial shock of arrival. Language, cultural framework, family, and community are all losses that when acknowledged support a refugee to move toward healthy adaptation. The refugee's entire world has shifted leaving refugees caught in the confusion of transitional grief. The past identity of the refugee is no longer valued and the refugee faces a complex period of adjustment. The work of grief is a critical expression that enables the refugee to accept the change necessary to enter into integration.

Program elements that engage this topic, normalize the emotions, educate the refugee, and allow expression of loss can be easily integrated into the migration process. Psycho-education that provides normalizing awareness of grief and encourages the expression of various emotions can serve to reduce anxiety and depression. As a community activity, or, as part of a cultural orientation it is critical that refugees and resettlement staff alike honor this process, allowing the majority of refugees to find a smoother path toward adaptation. Group-based activities can serve to identify the individuals who are exhibiting symptoms beyond the normal limits of grief.

Those who are exhibiting more severe symptoms will also benefit by receiving a foundation of grief work before addressing the more complex symptoms. Those who may need intensive therapeutic interventions benefit from the group activities that will help them to differentiate the challenges of normal acculturation with the symptoms of severe traumatic loss. Building on the groundwork of the group these individuals may have a greater capacity to benefit from individual work (Nichol \& Thompson, 2004; Weine et al., 2008). 
Building self-efficacy. The impact of self-efficacy on migratory adaptation has not been formally recognized in the US resettlement process. This study suggests that resettlement procedures and policy should consider creative responses based on the constructs of self-efficacy. Using the indicators within the instrument as a guide, strength-based interventions could be designed to enable refugee reflection on the areas of capacity they have brought with them. Mechanisms for increasing self-efficacious beliefs could be integrated into programs prior to the migration period. Identification of qualities of self-efficacy in the early months after migration can be a mechanism to encourage recognition and ongoing development of those beliefs.

These results are linked to constructs of resource development and posttraumatic growth. Refugees bring much strength and skills with them to resettlement that, too often, may be seen by the refugee to be dismissed. Therapeutic models with groups or with individuals reinforcing the refugees existing skills and richness of previous experiences should be a part of every resettlement program. More intentional engagement of refugee skill, in the early period of adjustment may help to link past capacity with adjustment to everything that is new.

Problems after migration. This research confirms that new problems encountered during early resettlement have significant impact on refugees. These results support literature suggesting that reducing the strain on refugees in the early stage of migration could mitigate distress as well as help to address specific emotional needs of refugees that will support adaptation (Weine, 2011). Specific program elements that address challenges and create mechanisms to ease refugees into new expectations or to gain new skills could be useful in reducing distress. Ultimately, the recognition of the 
impact of problems faced by refugees by program developers, rather than ignoring them, could be financially advantageous.

The challenge of migration includes fear of failure that can be reduced by guided access to new resources. The promotion of self-sufficiency is not incongruent with creating safety nets and strengths-based models that provide steppingstones to full time employment. The all in or all out full time work requirement in some agencies does not meet the needs of a significant minority of refugees and simply forces people into a survival mode as their state benefits come to an end.

Resettlement programs. Resettlement employment goals and refugee capacity building are not mutually exclusive. A model integrating these concepts with greater intention could pave the way toward a smoother adaptation. Recognizing that the need for connection (Weine, 2011), acknowledgement of migration expectations (Drachman, 1992), and support of efficacy (Beckerman \& Corbett, 2008) can help program developers to consider more creative approaches.

Group-based intervention models could be designed to support the expression of loss that acknowledges grief and then identifies areas of capacity. Program elements that include opportunities for individuals to identify the areas of gain that have become available to them in the new environment will encourage individual access to additional resources. Using strength-based approaches and intervention could build self-efficacy by establishing opportunities for interactive learning. The challenge to resettlement programs is the varying levels of capacity within the refugee population at any one time. However, a measure of capacity could be designed to link refugees with resources or systems that address a particular level of need. 
The commonly used empowerment approach within resettlement agencies of teaching new skills by demonstration is considered a useful tool for learning to ride the bus, household management, and other daily activities. A similar model could be developed to expand refugee comfort in new situations as well as expose them to workrelated activities and expectations. Program designs that use a social model could provide cross-training for refugees by refugees in specific areas of skill. Programs that empower new refugees with skill building interventions would also serve to more clearly identify refugees needing more specific support or intervention.

The literature suggests that there is a complex link between trauma, emotional distress, sense of capacity, and personal perceptions of loss all of which influence one another. As social workers we must sufficiently understand this interconnectedness in order to comfortable engage with the client's we serve. There is need for traumainformed models that provide guidance for interventions and engagement with refugee clients that do not depend on diagnostic symptomology. Rather than defining a refugee by their symptom we must enter into relationship with the whole person seeking together to find meaning that, for them, can facilitate healing.

\section{Considerations for Policy}

Historically, the US refugee program was considered a humanitarian one but in recent years the emphasis has shifted into an employment focus defined as selfsufficiency. When compared with lengthy benefit periods of socialized programs in Europe, refugees argue that US support is unfair. Some view the US program as creating a survival of the fittest approach that increases threat for some refugees (Vissicaro, 2009) while others believe the pressure of economic realities promote greater self-sufficiency. 
As agencies usher large numbers of refugees into rapid employment there is little identification of the factors that may impact success or failure with the only measure of self-sufficiency being employment. Policy makers could consider an expanded definition of refugee success that recognizes adaptation beyond staying in a job. Policy that recognizes elements of empowerment and other skill development could allow for more creative program responses that support refugees to reach adaptation.

\section{Considerations for Research}

The two aspects of this study that impact further research are the separation of the impact of anxiety and depression and the focus on the early months of migration. These are two areas that have not been sufficiently explored and additional research could significantly expand our knowledge.

Further research is necessary to establish firmer distinctions about the predictors of emotional distress in refugees. These findings, while significant, should be retested with other populations. It is important that this preliminary model for understanding migration adaptation at the early stage of resettlement be evaluated in further research.

\section{Strengths of the study}

A primary strength of this study is the focus on a critical time period for refugees, just following migration, during engagement with resettlement programs, and prior to employment. One strength of this study is the separate assessment of anxiety and depression providing results that differentiate the two aspects of emotional distress. Recognizing that while both sets of symptoms limit a refugee's ability to function, understanding the links between specific factors and each expression of distress can help improve clinical responses. 
In addition, this study identified several factors impacting emotional distress that have not been previously discussed in the literature. At the current stage of research related to refugee functioning, this study's increase of the impact of some factors and the reduction of impact of other factors provides a pathway to the continued exploration of this area of research.

\section{Limitations of the study}

One limitation of this study is sample size and the number of country of origin groups. More research needs to be conducted with a larger sample size and additional groups to assess the universality of these conclusions.

Another limitation is the use of the HSCL-25 cut-off value to determine a dichotomous label for the outcome variable. While the use of the cut-off value is a clinically sound choice and the analysis standard is met, the limitation is in the potentially very small difference between respondents. A respondent who scores 1.74 is not significant and one who scores 1.75 is significant, leaving two individuals with very similar results in two different categories. Future research to identify factors related to refugee mental health could try to find more distinctive measurable options for an outcome variable.

An area of limitation in this study is respondent recall when comparing results of instruments measuring past events with those measuring current events. The measures, all taken at the same time, asked respondents to rate events that occurred in the past, as well as, events in the present. It is natural for events of the past to be recalled with less intensity than those that are current. Creating the two sets of predictor variables and separating the analysis of prearrival characteristics from the current perceptions helped to 
minimize the temporal impact. A longitudinal study of one group over time, using a series of instruments that all measure current events and perceptions would make a significant contribution to the literature.

\section{Conclusion}

As stated previously, refugee capacity is defined as the refugee's ability to integrate, or adapt at least on some level, into life in the country of resettlement (Ager \& Strang, 2008; Ryan et al., 2008). While some of the study results may be common assumptions amongst people working in the area of resettlement, this empirical data is invaluable in supporting new perspectives on policy and programs with refugees. Creative interventions and activities that recognize existing qualities and empower refugees in the development of new skills will help to overcome the challenges during this critical period of migration. Combining elements of a strengths approach to the development of efficacy with improved resource access could create a program system that both empowers refugees and reduces symptoms of emotional distress. 


\section{REFERENCES}

Ager, A., \& Strang, A. (2008). Understanding integration: a conceptual framework. Journal of Refugee Studies, 21(2), 166-191. doi: 10.1093/jrs/fen016.

Alayarian, A. (2007). Trauma, resilience and creativity: examining our therapeutic approach in working with refugees. European Journal of Psychotherapy and Counselling 9(3), 313-324. doi: 10.1080/13642530701571682.

Allport, G. W. (1960). The open system in personality theory. Journal of Abnormal and Social Psychology, 61, 301-310.

Antonovsky, A. (1979). Health, Stress and Coping. San Francisco, Josey Bass.

Aragona, M., Pucci, D., Carrer, S., Catino, E., Tomaselli, A., Colosimo, F., \& Geraci, S. (2011). The role of post-migration living difficulties on somatization among firstgeneration immigrants visited in a primary care service. Ann Ist Super Sanita, 47(2), 207-213. doi: 10.4415/ANN_11_02_13.

Aragona, M., Pucci, D., Mazzetti, M., \& Geraci, S. (2012). Post-migration living difficulties as a significant risk factor for PTSD in immigrants: a primary care study. Italian Journal of Public Health, 9(3), 1-8. doi: 10.2427/7525.

Bandura, A. (1988). Self-efficacy conception of anxiety. Anxiety Research 1, 77-98.

Bandura, A. (1989). Social cognitive theory, Annals of child development. Greenwich, CT: JAI Press. 
Bandura, A. (1997). Self-efficacy: the exercise of control. New York: W.H. Freeman.

Bandura, A., Caprara, G., Barbaranelli, C., Gerbino, M., \& Pastorelli, C. (2003). Role of affective self-regulatory efficacy in diverse spheres of psychosocial functioning. Child Development 74(3), 769-782.

Beckerman, N., \& Corbett, L. (2008). Immigration and families: treating acculturative stress from a systemic framework. Family Therapy 35(2), 63-81.

Benight, C., \& Bandura, A. (2004). Social cognitive theory of posttraumatic recovery: the role of perceived self-efficacy. Behaviour Research and Therapy 42, 1129-1148. doi: 10.1016/j.brat.2003.08.008.

Berry, J. (2001). A psychology of immigration. Journal of Social Issues 57(3), 615-631.

Berry, J., Kim, U., Minde, T., \& Mok, D. (1987). Comparative studies of acculturative stress. International Migration Review 21(3), 491-511.

Bhugra, D. (2004). Migration and mental health. Acta Psychiatria Scandinavia, 109:243258

Bjorn, G. (2005). Ethics and interpreting in psychotherapy with refugee children and families. Norwegian Journal of Psychiatry, 59(5), 516-521.

Bremner, J. (2005). Does stress damage the brain? Understanding trauma related disorders from a mind body perspective. New York, NY, W. W. Norton and Company.

Briere, J., \& Scott, C. (2006). Principles of Trauma, A Guide to Symptoms, Evaluation, and Treatment. Thousand Oaks, CA, Sage. 
Brown, C., Schale, C., \& Nilsson, J. (2010). Vietnamese Immigrant and Refugee Women's Mental Health: An examination of age at time of arrival, Length of stay, Income and English proficiency. Multicultural Counseling and Development, 38, 66-76.

Bolton, P. (2001). Cross-cultural validity and reliability testing of a standard psychiatric assessment instrument without a gold standard. Journal of Nervous and Mental Disorders, 189(4), 238-242.

Bonanno, G. A. (2005). Clarifying and extending the construct of adult resilience. American Psychologist, 60, 265-667.

Carlsson, J., Mortensen, E., \& Kastrup, M. (2006). Predictors of mental health and quality of life in male tortured refugees. Norwegian Journal of Psychiatry, 60(1), $51-59$.

Carlsson, J., Olsen, D., Mortensen, E., \& Kastrup, M. (2006). Mental health and healthquality of life a 10-year follow-up of tortured refugees. The Journal of Nervous and Mental Disease, 194(10), 725-731. doi:

10.1097/01.nmd.0000243079.52138.b7.

Casado, B., Hong, M., \& Harrington, D. (2010). Measuring migratory grief and loss associated with the experience of immigration. Research on Social Work Practice 20(6), 611620. doi: 10.1177/1049731509360840.

Centers for Disease Control (2013). Suicide and Suicidal Ideation Among Bhutanese Refugees — United States, 2009-2012. Morbidity and Mortality Weekly Report 62(26), 533-536. 
Codrington, R., Iqbal, A., \& Segal, J. (2011). Lost in translation? Embracing the challenges of working with families from a refugee background. The Australian and New Zealand Journal of Family Therapy 32(2), 129-143.

Colic-Peisker, V., \& Walker, I. (2003). Human capital, acculturation and social identity: Bosnian refugees in Australia. Journal of Community \& Applied Social Psychology,13, 337-360. doi: 10.1002/casp.743.

Connor, K. (2006). Assessment of resilience in the aftermath of trauma. Journal of Clinical Psychiatry, 67(2), 46-49.

Corvo, K., \& Peterson, J. (2005). Posttraumatic stress symptoms, language acquisition, and self-sufficiency, A study of Bosnian refugees. Journal of Social Work 5(2), 205-219. doi:10.1177/1468017305054974.

Dalgard, O., Thapa, S., Hauff, E., McCubbin, M., \& Syed, H. 2006. Immigration, lack of control and psychological distress: findings from the Oslo Health Study. Scandinavian Journal of Psychology, 47, 551-558. doi: 10.1111/j.14679450.2006.00546.x.

Dekel, R., \& Hobfoll, S. (2007). The impact of resource loss on Holocaust survivors facing war and terrorism in Israel. Aging \& Mental Health, 11(2), 159-167. doi: $10.1080 / 13607860600736141$.

Derogatis, L., Cleary, P. (1977). Confirmation of the dimensional structure of the SCL90: A study in construct validity. Journal of Clinical Psychology, 33(4), 981-990.

Derogatis, L., Lipman, R., Rickels, K., Uhlenhuth, E., \& Covi, L. (1974) The Hopkins Symptom Checklist, (HSCL): A self-report symptom inventory. Behavioral Science, 19, 1-15. 
Drachman, D. (1992). A state-of-migration framework for service to immigrant populations. Social Work, 37(1), 68-72.

Dybicz, P. (2010) Confronting Oppression not Enhancing Functioning: The Role of Social Workers within Postmodern Practice, Journal of Sociology \& Social Welfare, 37(1).

Engel, G. (1996). From biomedical to biopsychosocial II. A personal odyssey. Family Systems and Health, 14, 434-449.

Ferren, P. (1999). Comparing perceived self-efficacy among adolescent Bosnian and Croatian refugees with and without posttraumatic stress disorder. Journal of Traumatic Stress, 12(3), 405-418.

Follette, V., Palm, K., \& Pearson, A. (2006). Mindfulness and trauma: Implications for treatment. Journal of Rational-Emotive \& Cognitive-Behavior Therapy, 24(1), 4558. doi: 10.1007/s10942-006-0025-2.

Folkman, S., \& Lazarus, R. (1986). Stress processes and depressive symptomology, Journal of Abnormal Psychology, 95(2), 107-113.

Fong, R., Greene, R. (2009). Risk, resilience and resettlement. Human behavior theory: A diversity framework. New Brunswick, NJ, Transactional Publishers.

Frankl, V. (1964). Man's search for meaning: An introduction to logotherapy. London: Hodder and Stoughton.

Fraser, M., Galinsky, M., \& Richman, J. (1999). Risk, protection and resilience: Toward a conceptual framework for social work practice, National Association of Social Workers, Inc., 131-141. 
Gafner, G., \& Benson, S. (2001). Indirect ego-strengthening in treating PTSD in immigrants from Central America. Contemporary Hypnosis, 18(3), 135-144.

Garbarino, J. (1995). The American war zone: what children can tell us about living with violence. Developmental And Behavioral Pediatrics, 16(6), 431-435.

George, M. (2012). Migration traumatic experiences and refugee distress: implications for social work practice. Clinical Social Work 40, 429-437, doi: 1007/s10615012-0397-y.

Germain, C., \& Gitterman, A. (1980). The life model of social work practice. New York: Columbia University Press.

Greene, R. (2007). Social work practice: A Risk and Resilience Perspective. Brooks and Cole, Montgomery, CA.

Greene, R., Galambos, C., \& Lee, Y., (2003). Resilience theory, theoretical and professional conceptualizations. Journal of Human Behavior in Social Environment, 8(4), 75-92.

Grotberg, E. (2003). Promoting resilience in displaced persons. The Ahfad Journal, 20(1), 27-36.

Harney, P. (2007). Resilience processes in context: contributions and implications of Bronfenbrenner's person-process-context model. Journal of Aggression, Maltreatment and Trauma, 14(3), 73-84. doi: 10.1300/J146v14n03_05.

Hobfoll, S. (1989). Conservation of resources a new attempt at conceptualizing stress. American Psychologist, 44(3), 513-524. 
Hobfoll, S. (2001). The influence of culture, community, and the nested-self in the stress process: advancing conservation of resources theory. Applied Psychology: An International Review, 50(3), 337-421.

Hobfoll, S. (2002). Social and psychological resources and adaptation. Review of General Psychology, 6(4), 307-320. doi: 10.1037//1089-2680.6.4.307.

Hobfoll, S. (2011). Conservation of resources theory: its implication for stress, health, and resilience. The Oxford handbook of stress, health, and coping, 127-144.

Hobfoll, S., Lilly, R., \& Jackson, A. (1992). Conservation of social resources and the self. The Meaning and measurement of social support, 125-141.

Hobfoll, S., Schroder, K., Wells, M., \& Malek, M. (2002). Communal versus individualistic construction of sense of mastery in facing life challenges. Journal of Social and Clinical Psychology, 21(4), 362-399.

Hobfoll, S., Spielberger, C., Breznitz, S., Figley, C., Folkman, S., Lepper-Green, B., \& van der Kolk, B. (1991). Addressing the stress of war and other traumatic events. American Psychologist, 46:8, 848-855.

Hodes, M., Jagdev, D., Chandra, N., \& Cunniff, A. (2008). Risk and resilience for psychological distress amongst unaccompanied asylum seeking adolescents. Child Psychology and Psychiatry, 49(7), 723-732. doi: 10.1111/j.14697610.2008.01912.x.

Hollifield, M., Eckert, V., Warner, T., Jenkins, J., Krakow, B., Ruiz, J., \& Westermeyer, J. (2005). Development of an inventory for measuring war-related events in refugees. Comprehensive Psychiatry, 46, 67-80. doi:

10.1016/j.comppsych.2004.07.003. 
Hollifield, M., Thompson Fullilove, M., \& Hobfoll, S. (2013). Climate change refugees. International and Cultural Psychology. doi: 10.1007/978-4419-9742-5_8.

Hollifield, M., Verbillis-Kolp, S., Farmer, B., Toolson, E., Woldehaimanot, T., Yamazaki, J., \& Soohoo, J. (2013). The refugee health screener-15 (RHS-15): development and validation of an instrument for anxiety, depression, and PTSD in refugees. General Hospital Psychiatry, 35(2), 202-209.

Hollifield M., Warner,T., Jenkins' J., Sinclair-Lian,N., Krakow, B., Eckert, V., \& Westermeyer, J. (2006). Assessing war trauma in refugees: Properties of the Comprehensive Trauma Inventory-104. Journal of Traumatic Stress, 19(4), $527-$ 540.

Hollifield, M., Warner, T., Lian, N., Krakow, B., Jenkins, J. H., Kesler, J., \& Westermeyer, J. (2002). Measuring Trauma and Health Status in Refugees: A critical Review. Journal of the American Medical Association, 5(288), 611-621.

Hooberman, J., Rosenfeld, B., Rasmussen, A., \& Keller, A. (2010). Resilience in traumaexposed refugees: the moderating effect of coping style on resilience variables. American Journal of Orthopsychiatry, 80(4), 557-563. doi:10.1111/j.19390025.2010.01060.x.

Hughes, A., Galbraith, D., \& White, D. (2011). Perceived competence: a common core for self-efficacy and self-concept. Journal of Personality Assessment, 93(3), 278289. doi: $10.1080 / 00223891.2011 .559390$.

Jacobsen, K., \& Landau, L. (2003). The dual imperative in refugee research: Some methodological and ethical considerations in social science research on forced migration, Disasters, 27(3), 185-206. 
Jamil, H., Farrag, M., Hakim-Larson, J., Kafaji, T., Abdulkhaleq, H., \& Hammad, A. (2007). Mental health symptoms in Iraqi refugees: posttraumatic stress disorder, anxiety, and depression. Journal of Cultural Diversity, 14(1), 19-25.

Keller, A., Lhewa, D., Rosenfeld, B., Sachs, E., Aladjem, A., Cohen, I., \& Porterfield, K. (2006). Traumatic Experiences and Psychological Distress in an Urban Refugee Population Seeking Treatment Services. The Journal of Nervous and Mental Disease, 194(3) 188-194.

Kennedy, J., Seymour, D., \& Hummel, B. (1999). A comprehensive refugee health screening program. Public Health Reports, 144, 469-477.

Kennedy, P. (2001). Working with survivors of torture in Sarajevo with Reiki. Complementary Therapies in Nursing \& Midwifery, 7, 4-7.

Kienzler, H. (2008). Debating war-trauma and posttraumatic stress disorder (PTSD) in an interdisciplinary arena. Social Science \& Medicine, 67, 218-227. doi:10.1016/j.socscimed.2008.03.030.

Kilpatrick, L., Suyenobu, B., Smith, S., Bueller, J., Goodman, T., Creswell, J., \& Naliboff, B. (2011). Impact of mindfulness-based stress reduction training on intrinsic brain connectivity. NeuroImage, 56, 290-298. doi: 10.1016/j.neuroimage.2011.02.034.

Kinzie J. (1982). Development and validation of a Vietnamese-language depression rating scale. American Journal of Psychiatry, 139(10), 1276-1281.

Kinzie, J. (2001). Psychotherapy for massively traumatized refugees: The therapist variable. American Journal of Psychotherapy, 55(4), 475-489. 
Kira, I., Ahmed, A., Mahmoud, V., Wassim, F. (2010). Group therapy model for refugee and torture survivors. Torture, 20, 108-113.

Kirmayer, L. (2002). The refugee's predicament. L' Evolution Psychiatrique, 67, 724742.

Kleijn, W., Hovens, J., \& Rodenburg, J. (2001). Posttraumatic stress symptoms in refugees: assessments with the Harvard trauma questionnaire and the Hopkins symptom checklist-25 in different languages. Psychological Reports, 88, 527-532.

Knipscheer, J., \& Kleber, R. (2006). The relative contribution of posttraumatic and acculturative stress to subjective mental health among Bosnian refugees. Journal of Clinical Psychology, 62(3), 339-353.

Koch, S., \& Weidinger-von der Recke, B. (2009). Traumatised refugees: An integrated dance and verbal therapy approach. The Arts in Psychotherapy, 36, 289-296. doi: 10.1016/j.aip.2009.07.002.

Kohrt, B., \& Harper, I. (2008). Navigating diagnoses: Understanding mind-body relations, mental health, and stigma in Nepal. Culture, Medicine and Psychiatry, 32, 462-491. doi: 10.1007/s11013-008-9110-6.

Kohrt, B., \& Hruschka, D. (2010). Nepali concepts of psychological trauma: The role of idioms of distress, ethnopsychology and ethnophysiology in alleviating suffering and preventing stigma. Culture, Medicine and Psychiatry, 34, 322-352. doi: 10.1007/s11013-010-9170-2.

Lacroix, M., \& Sabbah, C. (2011). Posttraumatic psychological distress and resettlement: The need for a different practice in assisting refugee families. Journal of Family Social Work, 14, 43-53. doi:10:1080/10522158.2011.523879. 
Lavik, N., Laake, P., Hauff, E., \& Solberg, O. (1999). The use of self-reports in psychiatric studies of traumatized refugees: Validation and analysis of the HSCL25. Norwegian Journal of Psychiatry, 53, 17-20.

Lazarus, R., \& Folkman, S. (1984). Stress, appraisal and coping. New York: Springer.

Lazarus, R., \& Folkman, S. (1987). Transactional theory and research on emotions and coping. European Journal of Personality 1:141-169.

Lie B. (2002). A 3-year follow-up study of psychosocial functioning and general symptoms in settled refugees, Acta Psychiatric Scandinavia, 106:415-425.

Lindert, J., von Ehrenstein, O., Priebe, S., Meilck, A., \& Brahler, E. (2009). Depression and anxiety in labor migrants and refugees: a systemic review and meta-analysis. Social Science \& Medicine, 69, 246-257. doi: 10.1016/j.socscimed.2009.04.032.

Littleton, H., Kumpula, M., \& Orcutt, H. (2011). Posttraumatic symptoms following a campus shooting: the role of psychosocial resource loss. Violence and Victims, 26(4), 461-475. doi: 10.1891/0886-6708.26.4.461.

Loughry, M., \& Flouri, F. (2001). The behavioral and emotional problems of former unaccompanied refugee children 3-4 years of after their return to Vietnam. Child Abuse \& Neglect, 25, 249-263.

Lu, Y., Lum, D., \& Chen, S. (2001). Cultural competency and achieving styles in clinical social work: A conceptual and empirical exploration. Journal of Ethnic and Cultural Diversity in Social Work, 9:3/4, 1-26. 
MacDuff, S., Grodin, M., \& Gardiner, P. (2011). The use of complementary and alternative medicine among refugees: A systematic review. Journal of Immigrant and Minority Health, 13, 538-599. doi: 10.1007/s10903-010-9318-8.

Maslow, A. (1954). Motivation and personality. New York, NY, Harper \& Row.

Maslow, A. (1962). Toward a psychology of being. Princeton, NJ: Van Nostrand.

Maslow, A. (1948). Some theoretical consequences of basic need-gratification. Journal of Personality, 16:402-416.

Matheson, K., Jorden, S., \& Anisman, H. (2008). Relations between trauma experiences and psychological, physical and neuroendocrine functioning among Somali refugees: mediating role of coping with acculturation stressors. Journal of Immigrant and Minority Health, 10, 291-304. doi: 10.1007/s10903-007-9086-2.

Meyers, L., Gamst, G., \& Guarino, A. (2006). Applied Multivariate Research: Design and Interpretation. Thousand Oaks CA., Sage Publications.

Miller, A., Sorkin, O., Wang, E., Feetham, S., Choi, M., \& Wilbur, J. (2006). Acculturation, social alienation, and depressed mood in midlife women from the former Soviet Union. Research in Nursing \& Health, 29, 134-146.

Miller, K., \& Rasmussen, A. (2009). War exposure, daily stressors and mental health in conflict and post-conflict settings: Bridging the divide between trauma focused and psycho-social frameworks. Social Science and Medicine, 70, 7-16. doi:10.1016/j.socscimed.2009.09.029.

Mirzamani S. M., Mohammadi, M. R., Mohoudi, J., G., \& Mirzamani, M. S. (2007). Validity of the PTSD Symptoms scale self-report in Iran. Iranian Journal of Psychiatry, 2, 120-123. 
Mollica, R. (2006). Healing Invisible Wounds: Paths to Hope and Recovery in a Violent World. Orlando, FL: Hartcourt, Inc.

Mollica, R., Caspi-Yavin, Y., Bollini, P., Truong, T., Tor, S., \& Lavelle, J. (1992). The Harvard Trauma Questionnaire: Validating a Cross Cultural Instrument for Measuring Torture, Trauma and Posttraumatic Stress Disorder in Refugees. Journal of Nervous Mental Diseases, 180:111-116.

Mollica, R., Wyshak, G., \& de Marneffe D. (1987). Indochinese versions of the Hopkins Symptom Checklist-25: a screening instrument for the psychiatric care of refugees. American Journal of Psychiatry, 144(4),497-500.

Momartin, S., Silove, D., Manicavasagar, V., \& Steel, Z. (2003). Dimensions of trauma associated with posttraumatic stress disorder (PTSD) caseness, severity and functional impairment: a study of Bosnian refugees resettled in Australia. Social Science \& Medicine, 57, 775-781.

Momartin, S., Silvove, D., Manicavasagar, V., \& Steel, Z. (2004). Comorbidity of PTSD and depression: associations with trauma exposure, symptom severity and functional impairment in Bosnian refugees resettled in Australia. Journal of Affective Disorders, 80, 231-238. doi: 10.1016/S0165-0327(03)00131-9.

Moodley, R., Sutherland, P., \& Oulanova, O. (2008). Traditional healing, the body and mind psychotherapy. Counselling Psychology Quarterly, 21(2), 153-165. doi: 10.1080/09515070802066870.

Moodley, R., \& Sutherland, P. (2010). Psychic retreats in other places: Clients who seek healing with traditional healers and psychotherapists. Counselling Psychology Quarterly, 23(3), 267-282. doi: 10.1080/09515070.2010.505748. 
Mui, A., and \& Kang, S. (2006). Acculturation stress and depression among Asian Immigrant Elders. Social Work, 51(3), 243-255.

Mutabaruka, J., Sejourne, N., Bui, E., Birmes, P., \& Chabrol, H. (2012). Traumatic grief and traumatic stress in survivors 12 years after the genocide in Rwanda. Stress and Health, 28, 289-296. doi: 10.1002/smi. 1429.

Nicholl, C., \& Thompson, A. (2004). The psychological treatment of posttraumatic stress disorder (PTSD) in adult refugees: A review of the current state of psychological therapies. Journal of Mental Health, 13(4), 351-362. Doi $10.1080 / 09638230410001729807$.

Nickerson, A., Bryant, R., Silove, D., \& Steel, Z. (2011). A critical review of psychological treatments of posttraumatic stress disorder in refugees. Clinical Psychology Review, 31, 399-417. doi: 10.1016/j.cpr.2010.10.004.

Oh, Y., Koeske, G., \& Sales, E. (2002). Acculturation, stress and depressive symptoms among Korean immigrants in the United States. The Journal of Social Psychology, 142(4), 511-526.

Onyut, L., Neuner, F., Schauer, E., Ertl, V., Odenwald, M., Schauer, M., \& Elbert, T. (2005). Narrative exposure therapy as a treatment for child war survivors with posttraumatic stress disorder: Two case reports and a pilot study in an African refugee settlement. BioMed Central Psychiatry, 5(7), 1-9. doi: 10.1186/1471244X-5-7.

Oruc, L., Kapetanovic, A., Pojskic, N., Miley, K., Forstbauer, S., Mollica, R., \& Henderson, D. (2008). Screening for PTSD and depression in Bosnia and Herzegovina: validating the Harvard Trauma Questionnaire and the Hopkins 
Symptom Checklist. International Journal of Culture and Mental Health, 1(2), 105-116.

Overland, G. (2011). Generating theory, biographical accounts and translation: a study of trauma and resilience. International Journal of Social Research Methodology, 14(1), 61-75. doi: 10.1080/13645579.2010.483078.

Pacquiao, D. (2008). Nursing care of vulnerable populations using a framework of cultural competence, social justice and human rights. Contemporary Nursing, 28(1-2), 189-197.

Palic, S., \& Elklit, A. (2011). Psychosocial treatment of posttraumatic stress disorder in adult refugees: A systematic review of prospective treatment outcome studies and a critique. Journal of Affective Disorders, 131, 8-23.

Paunovic, N., \& Ost, L. G. (2005). Psychometric properties of a Swedish Translation of the clinician-Administered PTSD scale-Diagnostic Version. Journal of Traumatic Stress, 18(2), 161-164.

Payne, M. (2005). Modern Social Work Theory, Lyceum Books, Chicago, Illinois.

Pearlin, L., Lieberman, M., Menaghan, E., Mullan, J. (1981). The Stress Process, Journal of Health and Social Behavior, 22, 337-356.

Peduzzi, P., Concato, J., Kemper, E., Holford, T., \& Feinstein, A., (1996). A simulatin study of the number of events per variable in logistic regression analysis. Journal of Clinical Epidemiology, 49, 1373-1379.

Peng, C., Lee, K., \& Ingersoll, G., (2002). An Introduction to Logistic Regression analysis and Reporting. The Journal of Educational Research, 96(1), 3-11. 
Petrocelli, J. (2003). Hierarchical Multiple Regression in counseling research: Common Problems and Possible Remedies. Measurement and Evaluation in Counseling and Development, 36,9-22.

Porter, M., \& Haslam, N. (2005). Predisplacement and postdisplacement factors associated with mental health of refugees and internally displaced persons. Journal of American Medical Association, 294(5), 602-612.

Potcky-Tripdi, M. (2003). Refugee economic adaption: Theory, Evidence and Implications for Policy and Practice. Journal of Social Service Research, 30(1), $63-88$.

Ranard, D. (2008). Refugees from Iraq. Washington, DC, Center for Applied Linguistics

Rousseau, C., Benoit, M., Gauthier, M., Lacroix, L., Alain, N., Rojas, M., \& Bourassa, D. (2007). Classroom drama therapy program for immigrant and refugee adolescents: A pilot study. Clinical Child Psychology and Psychiatry, 12(3), 451-465. doi: $10.1177 / 1359104507078477$.

Ryder, A., Alden, L., \& Paulhus, D. (2000). Is acculturation unidimensional or bidimensional? A head-to-head comparison in the prediction of personality, selfidentity, and adjustment. Journal of Personality and Social Psychology, 79(1), 4965. doi: $10.1037 / / 0022-3514.79 .1 .49$

Sargent, C., \& Larchanché, S. (2009). The construction of "cultural difference" and its therapeutic significance in immigrant mental health services in France. Culture, Medicine and Psychiatry, 33, 2-20. doi: 10.1077/s11013-008-9115-1 
Schwarzer, R., Jerusalem, M., \& Hahn, A. (1994). Unemployment, social support and health complaints: a longitudinal study of stress in East German refugees. Journal of Community \& Applied Psychology, 4, 31-45.

Schwarzer, R., \& Jerusalem, M. (1995). Generalized self-efficacy scale, Measures in health Psychology: A user's portfolio. Windsor UK, Nfer-Nelson.

Schweitzer R., Melville F., Steel Z., \& Lacherez P. (2002). Trauma, post-migration living difficulties, and social support as predictors of psychological adjustment in resettled Sudanese refugees. Australian New Zealand Journal of Psychiatry, $40,179-187$.

Schweitzer, R., Brough, M., Vromans, L., \& Asic-Kobe, M. (2011). Mental health of newly arrived Burmese refugees in Australia: contributions of pre-migration and post-migration experience. Australian and New Zealand Journal of Psychiatry, 45, 299-307.

Shannon, P., Im, H., Becher, E., Simmelink, J., Weiling, E., \& O’Fallon, A. (2012). Screening for war trauma, torture and mental health symptoms among newly arrived refugees: A National survey of U. S. Refugee Health Coordinators. Journal of Immigrant and Refugee Studies, 10:380-394.

Shuter, R. (1990). The centrality of culture. The Southern Communication Journal, 55, 237-249.

Siegel, C., Davis-Chambers, E., Haugland, G., Banks, R., Aponte, C., \& McCombs, H. (2000). Performance measures of cultural competency in mental health organizations. Administration and Policy in Mental Health, 28(2), 91-106. 
Silove, D., Sinnerbrink, I., Field, A., Manicavasagar, V., \& Steel, Z. (1997). Anxiety, depression and PTSP in asylum-seekers: associations with pre-migration and post-traumatic stressors. The British Journal of Psychiatry, 170, 351-357. doi: 10.1192/bjp.170.4.351.

Silove, D., Steel, Z., \& McGary (1998). Post-migration Living Problems. Acta Psychiatric Scandanavia, 97:175-183.

Silove, D., Steel, Z., McGorry, P., \& Mohan, P. (1998). Trauma exposure, postmigration stressors, and symptoms of anxiety, depression and post-traumatic stress in Tamil asylum-seekers: comparison with refugees and immigrants. Acta Psychiatrica Scandinavica, 97(3), 175-181.

Silove, D., Manicavasagar, V., Mollica, R., Thai, M., Khiek, D., Lavelle, J., \& Tor, S. (2007). Screening for depression and PTSD in a Cambodian population unaffected by war. The Journal of Nervous and Mental Disease, 195(2), 152-157.

Smith, G., \& Strain, J. (2002). George Engel's contribution to psychiatry. Australia and New Zealand Journal of Psychiatry, 36: 438-466.

So, J. (2008). Somatization as cultural idiom of distress: rethinking mind and body in a multicultural society. Counselling Psychology Quarterly, 21(2), 167-174. doi: $10.1080 / 09515070802066854$.

Sossou, M., Craig, C., Ogren, H., \& Schnak, M. (2008). A qualitative study of resilience factors of Bosnian refugee women resettled in the Southern United States. Journal of Ethnic \& Cultural Diversity in Social Work, 17(4), 365-385. doi: $10.1080 / 15313200802467908$.

Steele, W. (2003). Structured sensory interventions for children, adolescents, and 
parents. Trauma and Loss: Research and Interventions, 1(1), 8-20.

Stoll, K., \& Johnson, P. (2007). Determinants of the psychosocial adjustment of Southern Sudanese men. Journal of Refugee Studies, 20(4), 621-638. doi: 10.1093/jrs/fem037.

Strumpher J. (2005). Standing on shoulders of giants: Notes on early positive psychology. South African Journal of Psychology, 35(1) 21-45.

Sue, D. W., \& Sue, D. (2003). Counseling the Culturally Diverse, Theory and Practice. New York, NY, Wiley and Sons.

Sulaiman-Hill, C., \& Thompson, S. (2011). Learning to fit in: an exploratory study of general perceived self-efficacy in selected refugee groups. Journal of Immigrant and Minority Health, 15, 125-131. doi: 10.1007/s10903-011-9547-5.

Tabachnik, B., \& Fidell, L. (2007). Using Multivariate Statistics, Fifth Edition. Boston MA., Pearson Education.

Talwar, S. (2007). Accessing traumatic memory through art making: An art therapy trauma protocol (ATTP). The Arts in Psychotherapy, 34, 22-35. doi: 10.1016/j.aip.2006.09.001.

Teodorescu, D., Siqveland, J., Heir, T., Hauff, E., Wentzel-Larsen, T., \& Lien, L. (2012). Posttraumatic growth, depressive symptoms, posttraumatic stress symptoms, postmigration stressors and quality of life in multi-traumatized psychiatric outpatients with a refugee background in Norway. Health and Quality of Life Outcomes, 10, 84-99. doi: 10.1186/1477-7525-10-84. 
Terheggen, M., Stroebe, M., \& Kleber, R. (2001). Western conceptualizations and Eastern experience: A cross-cultural study of traumatic stress reactions among Tibetan refugees in India. Journal of Traumatic Stress, 14(2) 391-402.

Thompson, R., Arnkoff, D., \& Glass, C. (2011). Conceptualizing mindfulness and acceptance as components of psychological resilience to trauma. Trauma, Violence, \& Abuse, 12(4), 220-235. doi: 10.1177/1524838011416375.

Tseng, W. (2004). Culture and psychotherapy: Asian perspectives. Journal of Mental Health, 13(2), 151-161. doi: 10.1080/09638230410001669282.

United States State Department, Bureau of Population (2010). Refugees and Migration, Report for Fiscal Year 2010. Retrieved from www.state.gov/j/prm/releases/statistics/181160.htm.

United States Department of Health and Human Services, The Refugee Act, Administration for children and Families, (1999). Office of refugee resettlement website. Retrieved from www.acf.hhs.gov/programs/orr/policy/refact1.htm.

United States Department of Homeland Security, (2011). Refugees and Asylees: 2011, Annual Flow Report. Retrieved from www.migrationpolicy.org/article-andasylees-united-states.

United Nations High Commission on Refugees, (2002), An International Handbook to Guide Reception and Integra tion, Chapter 3.1, Planning for Optimal Mental Health. Retrieved from www.unhcr.org/cgibin/texis/vtx/home/opendocPDFViewer.html?docid=3d98623a 4\&query=health. 
United Nations High Commission on Refugees, (2010), 2010 Global Trends Report.

Retrieved from UNHCR website: www.unhcr.org/4dfall11499.html.

United Nations High Commissioner on Refugees, (2011). Handbook and Guidelines on

Procedures and Criteria for Determining Refugee Status under the 1951

Convention and the 1967 Protocol Relating to the Status of Refugees. Retrieved

from UNHCR website: www.unhcr.org/refworld/docid/4f33c8d92.html

United Nations High Commission on Refugees, (2013). Country operations profiles.

Retrieved from www.unhcr.org/cgi-

bin/texis/vtx/page?page=49e4877d64877d6\&submit.

Vaage, A., Thomsen, P., Silove, D., Wentzel-Larsen, Ta, T., \& Hauff, E. (2010). Longterm mental health of Vietnamese refugees in the aftermath of trauma. The British Journal of Psychiatry, 196, 122-125. doi: 10.1192/bjp.bp.108.059139.

van de Kolk, B., McFarlane, A., \& Weisaeth S. (Eds.) (1996). Traumatic stress, the effects of overwhelming experiences on mind, body and society. New York, NY, Guilford Press.

van der Kolk, B., Roth, S., Pelcovitz, D., Sunday, S., \& Spinazzola, J. (2005). Disorders of extreme stress: The empirical foundation of a complex adaptation to trauma. Journal of Traumatic Stress, 18(5), 389-399. doi: 10.1002/jts.20047.

Vissicaro, P. (2009). Dance, community, and the reconfiguration of space: Resettlement strategies among African refugees in Phoenix Arizona. Review of Human Factor Studies, 15 (1), 48-66. 
Wallin, A., \& Ahlstrom, G. (2010). From diagnosis to health: a cross-cultural interview study with immigrants from Somalia. Scandinavian Journal of Caring Sciences, 24, 357-363.

Walter, K., Horsey, K., Palmieri, P., \& Hobfoll, S. (2010). The role of protective selfcognitions in the relationship between childhood trauma and later resource loss. Journal of Traumatic Stress, 23(2), 264-273. doi: 10.1002/jts.20504.

Weine, S. (2011). Developing preventive mental health interventions for refugee families in resettlement. Family Process, 50(3), 410-430.

Weine, S., Danieli, Y., Silove, D., Van Ommeren, M., Fairbank, J., \& Saul, J. (2002). Guidelines for international training in mental health and psychosocial interventions for trauma exposed populations in clinical and community settings. Psychiatry, 65(2), 156-163.

Weine, S., Hoffman, Y., Ware, N., Tugenberg, T., Hakizimana, L., Dahnweigh, G., \& Wagner, M. (2011). Secondary migration and relocation among African refugee families in the United States. Family Process, 50(1), 27-44.

Weine, S., Kulauzovic, Y., Klebic, A., Besic, S., Mujagic, A., Muzurovic, J., \& Pavkovic, I. (2008). Evaluating a multiple-family group access intervention for refugees with PTSD. Journal of Marital and Family Therapy, 34(2), 149-164.

Wessells, M., \& Kostelny, K. (2012). Everyday distress: psychosocial and economic impact of forced migration on children and families. The Oxford handbook of poverty and child development $640-655$. 
Worster, A., Fan, J., \& Ismaila, A., (2007). Understanding linear and logistic regression analysis: Pedagogical Tools and Models. Canadian Journal of Emergency Medicine 9(2), 111-113.

Yakushko, O. (2010). Stress and Coping strategies in the lives of recent immigrants: A grounded theory. International Journal of the Advancement of Counselling, 32, 256-273.

Yohani, S., \& Hagen, K. (2010). Refugee women survivors of war related sexual violence: a multicultural framework for service provision in resettlement countries, Intervention, 8(3), 207-222. 
Appendix 1

\section{Basic Health Information}

1. Date of Birth (mo/day/yr):

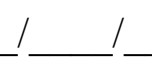

Current Age:

2. Gender:

Male

Female

3. Country of Birth:

4. Years of education: (Circle number)

$$
\begin{array}{llllllllllllllllll}
0 & 1 & 2 & 3 & 4 & 5 & 6 & 7 & 8 & 9 & 10 & 11 & 12 & 13 & 14 & 15 & 16 & \text { more than } 16
\end{array}
$$

5. Marital Status: (Check only one)

_ Married _ Not Married

6. Total number of people residing in household including yourself: (circle number)

$$
\begin{array}{llllllll}
1 & 2 & 3 & 4 & 5 & 6 & 7 & \text { more than } 7
\end{array}
$$

7. What is the combined annual income of your family? (Circle one)
A. $0-\$ 15,000$
B. $\$ 15,000-20,000$
C. $\$ 20,000-\$ 25,000$
D. $\$ 25,000-\$ 30,000$
E. $\$ 30,000-\$ 40,000$
F. Greater than $\$ 40,000$

8. How many hours per week do you work at your job on average? Hours

9. How many months have you had a medical coupon? (Circle one)

$$
\begin{array}{lllllllll}
1 & 2 & 3 & 4 & 5 & 6 & 7 & 8 & \text { more than } 8
\end{array}
$$

10. Before migrating to the United States were you living in:
a. a refugee camp
b. your home country of origin
c. in a temporary home 
Appendix 2

Comprehensive Trauma Inventory - Short Form 12
Instructions: Circle the best response for each item

\begin{tabular}{|l|c|c|c|c|c|}
\hline & No & $\begin{array}{c}1-2 \\
\text { times }\end{array}$ & $\begin{array}{c}3-12 \\
\text { times }\end{array}$ & $\begin{array}{c}13-50 \\
\text { times }\end{array}$ & $\begin{array}{c}51+ \\
\text { times }\end{array}$ \\
\hline $\begin{array}{l}\text { 1.Did you have to flee or hide } \\
\text { from soldiers or enemies, or } \\
\text { were you threatened with harm } \\
\text { or serious danger? }\end{array}$ & 1 & 2 & 3 & 4 & 5 \\
\hline $\begin{array}{l}\text { 2. Were you injured by } \\
\text { chemicals, bullets, or } \\
\text { explosives? }\end{array}$ & 1 & 2 & 3 & 4 & 5 \\
\hline $\begin{array}{l}\text { 3. Were you interrogated or } \\
\text { physically searched? }\end{array}$ & 1 & 2 & 3 & 4 & 5 \\
\hline $\begin{array}{l}\text { 4. Were you detained or } \\
\text { imprisoned? }\end{array}$ & 1 & 2 & 3 & 4 & 5 \\
\hline $\begin{array}{l}\text { 5. Were you humiliated in front } \\
\text { of others (stripped naked, } \\
\text { insulted, or beaten)? }\end{array}$ & 1 & 2 & 3 & 4 & 5 \\
\hline $\begin{array}{l}\text { 6. Did you see others being } \\
\text { severely hurt or killed? }\end{array}$ & 1 & 2 & 3 & 4 & 5 \\
\hline $\begin{array}{l}\text { 7. Did you help severely } \\
\text { wounded people or handle } \\
\text { dead bodies? }\end{array}$ & 1 & 2 & 3 & 4 & 5 \\
\hline $\begin{array}{l}\text { 8. Did you have your home, } \\
\text { business or important personal } \\
\text { property confiscated? }\end{array}$ & 1 & 2 & 3 & 4 & 5 \\
\hline $\begin{array}{l}\text { 9. Did you experience severe } \\
\text { family conflict because of the } \\
\text { war? }\end{array}$ & 1 & 2 & 3 & 4 & 5 \\
\hline $\begin{array}{l}\text { 10. Did you have to flee or } \\
\text { move to a new area because of } \\
\text { war or discrimination? }\end{array}$ & 1 & 2 & 3 & 4 & 5 \\
\hline $\begin{array}{l}\text { 11. Were you separated from a } \\
\text { family member because of the } \\
\text { war problems? }\end{array}$ & 1 & 2 & 3 & 4 & 5 \\
\hline $\begin{array}{l}\text { 12. Were you afraid that you } \\
\text { would be sent back to your } \\
\text { country from a refugee camp? }\end{array}$ & 1 & 2 & 3 & 4 & 5 \\
\hline
\end{tabular}


Appendix 3

Generalized Self-efficacy Scale

\begin{tabular}{|c|c|}
\hline Appendix & English version by Ralf Schwarzer \& Matthias Jerusalem, 1995 \\
\hline & $\begin{array}{l}1 \text { I can always manage to solve difficult problems if I try hard } \\
\text { enough. }\end{array}$ \\
\hline & $\begin{array}{l}2 \\
\begin{array}{l}\text { If someone opposes me, I can find the means and ways to get } \\
\text { what I want. }\end{array}\end{array}$ \\
\hline & 3 It is easy for me to stick to my aims and accomplish my goals. \\
\hline & \begin{tabular}{l|l}
4 & I am confident that I could deal efficiently with unexpected events. \\
\end{tabular} \\
\hline & \begin{tabular}{l|l}
5 & $\begin{array}{l}\text { Thanks to my resourcefulness, I know how to handle unforeseen } \\
\text { situations. }\end{array}$ \\
\end{tabular} \\
\hline & \begin{tabular}{l|l}
6 & I can solve most problems if I invest the necessary effort. \\
\end{tabular} \\
\hline & \begin{tabular}{l|l}
7 & $\begin{array}{l}\text { I can remain calm when facing difficulties because I can rely on my } \\
\text { coping abilities. }\end{array}$
\end{tabular} \\
\hline & 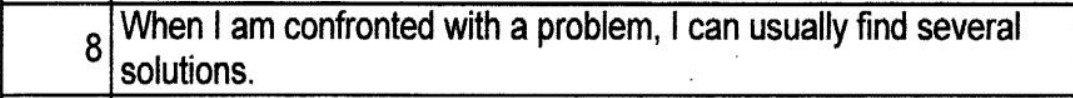 \\
\hline & 9 If I am in trouble, I can usually think of a solution. \\
\hline & $\begin{array}{l}10 \\
\text { I can usually handle whatever comes my way. }\end{array}$ \\
\hline $\begin{array}{l}\text { Response } \\
\text { Format }\end{array}$ & $1=$ Not at all true $2=$ Hardly true $3=$ Moderately true $4=$ Exactly true \\
\hline
\end{tabular}




\section{Appendix 4}

HOPKINS SYMPTOM CHECKLIST - 25

$\begin{array}{lll}\text { Name } & \text { Date } & \text { Clinician } \\ \text { Sate of Birth } \_ & \text {Sex } \_ \text {Marital Status } \\ \text { Arrival date } & \text { Psychiatric diagnosis }\end{array}$

\section{Instructions:}

Listed bellow are some symptoms or problems that people sometimes have. Please read each one carefully and decide how much the symptoms bothered of distressed you in the last week, including today. Place a check in the appropriate column.

\begin{tabular}{|l|l|c|c|c|}
\hline PART I & $\mathbf{1}$ & $\mathbf{2}$ & $\mathbf{3}$ & $\mathbf{4}$ \\
\hline & Not at all & A little & Quite a bit & Extremely \\
\hline 1. Suddenly scared for no reason & & & & \\
\hline 2. Feeling fearful & & & & \\
\hline $\begin{array}{l}\text { 3. Faintness, dizziness, or } \\
\text { weakness }\end{array}$ & & & & \\
\hline $\begin{array}{l}\text { 4. Nervousness or shakiness } \\
\text { inside }\end{array}$ & & & & \\
\hline 5. Heart pounding or racing & & & & \\
\hline 6. Trembling & & & & \\
\hline 7. Feeling tense or keyed up & & & & \\
\hline 8. Headaches & & & & \\
\hline 9. Spells of terror or panic & & & & \\
\hline 10 Feeling restless, can't sit still & & & & \\
\hline
\end{tabular}




\begin{tabular}{|c|c|c|c|c|}
\hline \multirow{3}{*}{$\begin{array}{l}\text { PART II } \\
\text { DEPRESSION SYMPTOMS } \\
\text { 11. Felling low in energy, slowed } \\
\text { down }\end{array}$} & 1 & 2 & 3 & 4 \\
\hline & Not at all & A little & Quite a bit & Extremely \\
\hline & & & & \\
\hline \multicolumn{5}{|l|}{ 12. Blaming yourself for things } \\
\hline \multicolumn{5}{|l|}{ 13. Crying easily } \\
\hline \multicolumn{5}{|l|}{$\begin{array}{l}\text { 14. Loss of sexual interest and } \\
\text { pleasure }\end{array}$} \\
\hline \multicolumn{5}{|l|}{ 15. Poor appetite } \\
\hline \multicolumn{5}{|l|}{$\begin{array}{l}\text { 16. Difficulty falling asleep, } \\
\text { staying asleep }\end{array}$} \\
\hline \multicolumn{5}{|l|}{$\begin{array}{l}\text { 17. Feeling hopeless about the } \\
\text { future }\end{array}$} \\
\hline \multicolumn{5}{|l|}{ 18. Feeling blue } \\
\hline \multicolumn{5}{|l|}{ 19. Feeling lonely } \\
\hline \multicolumn{5}{|l|}{ 20. Thoughts of ending your life } \\
\hline \multicolumn{5}{|l|}{$\begin{array}{l}\text { 21. Feeling of being trapped or } \\
\text { caught }\end{array}$} \\
\hline \multicolumn{5}{|l|}{$\begin{array}{l}\text { 22. Worrying too much about } \\
\text { things }\end{array}$} \\
\hline \multicolumn{5}{|l|}{ 23. Feeling on interest in things } \\
\hline \multicolumn{5}{|l|}{ 24. Feeling everything is an effort } \\
\hline 25. Feelings of worthlessness & & & & \\
\hline
\end{tabular}




\title{
Hopkins Symptom Checklist-25 Scoring
}

\author{
Items 1-10 Anxiety \\ Items 11-25 Depression \\ Item Average \\ Anxiety: Sum $1-10 \div 10$ \\ Depression: Sum 11-25 $\div 15$

Discrete
$\begin{array}{ll}\text { Anxiety: } & \geq 1.75=\text { "case" or } \\ & <1.75=\text { "non-case" or } \\ \text { Depression: } & \geq 1.75=\text { "case" or } \\ & <1.75=\text { "non-case" or }\end{array}$


Appendix 5

\section{Post-migratory Living Problems}

$\begin{array}{lllll}\text { No problem } & \text { A mild } & \text { A moderate } & \text { A serious } & \text { A very } \\ \text { at all } & \text { problem } & \text { problem } & \text { problem } & \text { serious problem }\end{array}$

1. Interviews by immigration

2. Conflict with immigration officials

3. No permission to work

4. Fears of being sent home

5. Worries about not getting health treatment

6. Poor access to emergency medical care

7. Poor access to long-term medical care

8. Poor access to dentistry care

9. Poor access to counseling services

10. Little government help with welfare

11. Little help with welfare from charities

12. Delays in processing your application

13. Separation from family

14. Worries about family back at home

15. Unable to return home in emergency

16. Communication difficulties

17. Discrimination

18. Not being able to find work

19. Bad job conditions

20. Poverty

21. Loneliness and boredom

22. Isolation

23. Poor access to the foods you like 


\title{
Appendix 6
}

\section{COR: Psychosocial and Economic Resources}

\begin{abstract}
LOSSES
We are interested the extent to which you have experienced a loss in any of the list of resources below \{during the last year\}

A loss of resources occurs when the resource has decreased in availability to you (e.g. loss of personal health). If you have experienced "loss" in any of the resources in the last six months, you would rate that "loss" from 1 to $4(1=a$ little, to $4=$ a great deal of $)$ and write your response in the "loss" column. If the availability of the resource has not changed, or the resource is not applicable, you would rate your " loss" as a 0 (zero = not at all / not applicable).
\end{abstract}

PLEASE NOTE: DO NOT RATE the availability of the resource to you. We are only interested in the LOSS of the resource.

FOR EXAMPLE: RESOURCE item 14 - "Status / Seniority at work:" If the status / seniority of your during the last year is still the same as today then you write a "0". If you had experienced "no loss" in the status / seniority of your job during that time then you would also write a " 0 " (zero=not at all/not applicable). 


\section{LOSSES}

$\begin{array}{llllll} & \text { "A little" } & & \text { "A great deal of" } \\ \underset{0}{4} & \mathbf{1} & \mathbf{2} & \mathbf{3} & 4\end{array}$

Rate your responses from 1 (a little loss) to 4 (a great deal of loss) for the following items. If you experienced no loss of that item put a 0 (zero $=$ not at all $/$ not applicable).

1. family stability 1

2. feeling that I am successful 2

3. adequate clothing 3

4. stable employment 4

5. personal health 5

6. good relationship with my children 1

7. feeling valuable to others 2

8. adequate food 3

9. necessary tools for work 4

10. spouse/partner health 5

11. intimacy with spouse or partner 1

12. hope 2

13. providing children's essentials 3

14. status/seniority at work 4

15. health of family/close friends 5

16. involvement in formal place of worship, (temple, mosque, church, etc.) 1 
17. feeling that I have control over my life 2

18. money for extras 3

19. role as a leader 4

20. children's health 5

21. companionship 1

22. feeling that my life is peaceful 2

23. adequate income 3

24. help with child care 1

25. feeling that my life has meaning/purpose 2

26. money for transportation 3

27. acknowledgement of my accomplishments 1

28. positive feelings about myself 2

29. medical insurance 3

30. ability to communicate well 2

31. housing that suits my needs 3 


\section{COR: Psychosocial and Economic Resources}

\section{GAINS}

We are also interested the extent to which you have experienced a gain in any of the list of resources below \{during the last year\}

Gain of resources occurs when the availability of a particular resource has increased for you (e.g., you have gained status/seniority at work). If you have experienced "gain" in any of the resources in the last 6 months, you would rate that "gain" from 1 to $4(1=a$ little, to $4=$ a great deal of)) and write your response in the "gain" column. If the availability of the resource is unchanged to you, or the resource is not applicable, you would write a 0 (zero $=$ not at all $/$ not applicable).

PLEASE NOTE:

DO NOT RATE the availability of the resource. We are only interested in the GAIN you have experienced in the resource.

FOR EXAMPLE:

RESOURCE item 18- "Money for extras"-: If you had an increase in money for extras during the last year and you still do now, then you would rate the extent of the gain as "0". 


\section{GAINS}

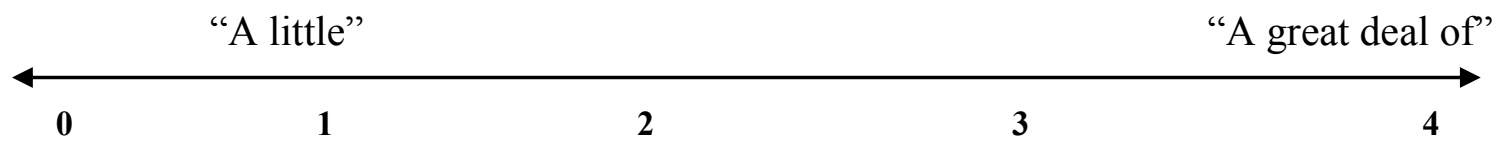

Rate your responses from 1 (a little gain) to 4 (a great deal of gain) for the following items. If you experienced no gain of that item put a 0 (zero = not at all / not applicable).

1. family stability 1

2. feeling that I am successful 2

3 . adequate clothing 3

4. stable employment 4

5. personal health 5

6. good relationship with my children 1

7. feeling valuable to others 2

8. adequate food 3

9. necessary tools for work 4

10. spouse/partner health 5

11. intimacy with spouse or partner 1

12. hope 2

13. providing children's essentials 3

14. status/seniority at work 4

15. health of family/close friends 5

16. involvement in formal place of worship, (temple, mosque, church, etc.) 1

17. feeling that I have control over my life 2

18. money for extras 3

19. role as a leader 4

20. children's health 5

21. companionship 1

22. feeling that my life is peaceful 2

23. adequate income 3

24. help with child care 1

25. feeling that my life has meaning/purpose 2

26. money for transportation 3

27. acknowledgement of my accomplishments 1

28. positive feelings about myself 2

29. medical insurance 3

30. ability to communicate well 2

31 . housing that suits my needs 3 


\section{CURRICULUM VITA}

NAME: $\quad$ Susan Heffner Rhema

ADDRESS: 212 West Ormsby Avenue

Louisville KY 40203

DOB: $\quad$ Reading, Pennsylvania- November 13, 1958

EDUCATION: $\quad \begin{aligned} & \text { A. B., Social Work } \\ & \text { Albright College, Reading, Pennsylvania } \\ & 1976-80\end{aligned}$
M.S.W., Community Organizing
University of Maryland at Baltimore, Baltimore, Maryland
1980-83
Ph. D., Social Work
University of Louisville, Kent School of Social Work, Louisville,
Kentucky
2012

AWARD: Dean's Citation

University Of Louisville

2014

LICENSE: Licensed Clinical Social Worker, (LCSW), in the state of Kentucky since 2004 and in the state of Arizona since 1993.

INTERNATIONAL

EXPERIENCE: $\quad$ Lived in Kenya, East Africa; Peru South America; and Mexico working in Community Organizing and Community Development for Non-Governmental Organizations. Provided oversight to funds management, and technical support for housing projects. Lead community based development projects and community organizing of women's economic and family enhancement development projects.

Traveled extensively to over 25 countries throughout Europe, Central America, South America, the Middle East, Central Asia, 
and East Asia working with international agencies, evaluating programs and personnel.

LANGUAGE

SKILLS: $\quad$ Spanish- Conversational

RESEARCH

EXPERIENCE: Consultant to a Robert Woods Johnson Foundation Grant, (2010), Seattle, Washington for the development and testing of the Refugee Health Screen Version -1

Contributor to the Kentuckiana Regional Planning and Development Agency, (KIPDA), for the Diabetes Prevention and Control Research Project, funded by the Centers for Disease Control, (CDC).

\section{PUBLICATIONS:}

Rhema, S., Gray, A., Verbillis-Kolp, S., Farmer, B., \& Hollifield, M. (2014). Mental Health Screening. In Annamalai, A., (Ed.), Refugee Health Care-An Essential Medical Guide (pp. 163-171). NewYork, NY, Springer Publications.

Faul, A.C., Gordon, B., D'Ambrosio, J.G., Ferrell, G., Tucker, M., Schapmire, T.J., Morgan, F., Thompson, J., Rhema, S., Miller, J.D., Boamah, D.A., Brown, L., Boes, R.C., Zheng, Y., Lawson, T.R. (2013). Academia and the Aging Network. 38th Annual N4A Conference and Tradeshow, Louisville, KY, July 27-31.

Miller, J., Rhema, S., Faul, A., D'Ambrosio, J., Yankeelov, P., Amer R., \& Clark, R., (2012) Strength in Process: Using Concept Mapping to Inform Community Coalition Development, Journal of Community Practice, 20:4, 432-456, DOI:

10.1080/10705422.2012.736074

Rhema, S., (2012). Universal assessment: Reframing critical thinking to enhance culturally competent practice skills, Council on Social Work Education, (CSWE).

Miller, J., Rhema, S., Faul, A., \& D'Ambrosio, J. (2012). The Promise of Social Work in Community Organizing: A Pragmatic Approach, Council on Social Work Education, (CSWE).

Miller, J., Rhema, S., Faul, A., D’Ambrosio, J., \& Yankeelov, P. (2012). The Use of Concept Mapping to Create a Coalition Logic Model and Evaluation Tool, Society for Social Work and Research, (SSWR).

Rhema, S., \& Segretto, R. (2011). Effective Techniques for Working with Immigrant, Refugee and Limited English Proficient Clients, Council on Social Work Education, (CSWE). 
INVITED PRESENTATIONS:

Best Practices for working with Refugees, Community Action of Southern Kentucky, Bowling Green, Kentucky, November 2013.

Best Practices for working with Refugees, Boys and Girls Haven, Louisville, Kentucky, April 2013.

Challenges in Refugee Mental Health, Cuban Haitian Entrant Program Conference, August 2012, Miami, Florida

Improving Response to reported Domestic Violence in Immigrant and Refugee Communities- A Cross Cultural perspective, Kentucky Domestic Violence Association Conference, presented November 2011, Lexington, Kentucky.

New Eyes for a New Land, Plenary presentation for the Coalition on Intimate Violence in International Communities conference entitled, The Intersection of Culture and Trauma: A Summit to improve access for Immigrant and Refugee Survivors of Sexual and Domestic Violence, May 27, 2011, Louisville, Kentucky.

Working with Refugee Clients: Best Clinical Practices and Treatment of Refugee Mental Health Issues”, Kentucky Office For Refugees- sponsor, presented May 17 and 18, 2011, Louisville, Kentucky

These Kids are Ours, Kentucky Teaching English as a Second Language Association Conference, September 2009, Louisville, Kentucky.

Finding the Human Connection in the Journey of Acculturation, Society for Intercultural Education Training and Research, Raleigh, North Carolina, April 2009.

Supporting Refugee Students, National Refugee Conference, Chicago, Illinois, September 2008.

Facing the Challenges of Acculturation, National Somali Bantu Conference, Louisville, Kentucky, August 2008.

Treating Refugee Trauma, Church World Service, Albuquerque New Mexico, August, 2008 